\title{
ESTUDO MICROTERMOMÉTRICO DOS FLUIDOS HIDROTERMAIS RELACIONADOS COM A MINERALIZACÃO AURÍFERA DE MONTES ÁUREOS, NW DO MARANHÃO
}

\author{
HUMBERTO SABRO YAMAGUTI ${ }^{1} \&$ RAIMUNDO NETUNO VILLAS $^{2}$
}

\begin{abstract}
MICROTHERMOMETRIC STUDY OF THE HYDROTHERMAL FLUIDS RELATED TO THE MONTES AUREOS GOLD MINERALIZATION, NW MARANHÃO The Montes Áureos gold mineralization occurred within the Tentugal Shear Zone which is an approximately $100 \mathrm{~km}$ long, $15 \mathrm{~km}$ wide NW-SE- trending structure that marks the south-southwest boundary of the São Luís craton and corresponds to the most deformed rocks of the Gurupi mobile belt. The ore bodies are hosted by the Paleoproterozoic metavolcanic and metasedimentary rocks of the Gurupi Group, which have been metamorphosed under greenschist to low amphibolite facies conditions. A superimposed hydrothermal event generated a system of vein and veinlets both concordant and discordant to the rock foliation. Gold occurs in up to $2 \mathrm{~cm}$ thick, late-tectonic quartz + carbonate veins or veinlets associated with arsenopyrite, pyrite and minor chalcopyrite. The spatial distribution of the mineralized zones defines lenticular to tabular bodies with gold contents less than $2 \mathrm{ppm}$. Textural features and time relationships between hydrothermal and metamorphic assemblages indicate that the mineralization followed the metamorphic peak and that gold occurs in at least two different forms: 1) isolated grains deposited simultaneously with sulfides; and 2) in microfractures in arsenopyrite and pyrite. Gold had been most likely transported by the sulphur complex $\left[\mathrm{Au}(\mathrm{HS})_{2}^{-}\right]$in an aqueous-carbonic, low salinity fluid $\left(2-8 \mathrm{wt} \% \mathrm{NaCl}\right.$ equiv.) at temperatures $£ 450^{\circ} \mathrm{C}$. Deposition took place at a temperature range from 260 to $350^{\circ} \mathrm{C}$. For the prevailing value of $300^{\circ} \mathrm{C}$, confirmed by the chlorite geothermometer, pressure estimates fall between 1.3 and $2.8 \mathrm{Kbar}$, corresponding to depths of $4-8.5 \mathrm{~km}$. Fluids related to the systems $\mathrm{CO}_{2} \pm \mathrm{CH}_{2}, \mathrm{H}_{2} \mathrm{O}_{-} \mathrm{CO}_{2}-$ $\mathrm{NaCl} \pm \mathrm{CH}_{4} \pm \mathrm{MgCl}$ and/or $\mathrm{FeCl}_{2}$ and $\mathrm{H}_{2} \mathrm{O}-\mathrm{NaCl} \pm \mathrm{MgCl}$ and/or $\mathrm{FeCl}_{2}$ circulated through the Montes Áureos rocks. The aqueouscarbonic fluids are considered most likely to be products of devolatization reactions of carbon-bearing sedimentary rocks at temperature probably above $500^{\circ} \mathrm{C}$. Initially homogeneous, these fluids have undergone immiscibility and were then trapped in fluid inclusions with different $\mathrm{H}_{2} \mathrm{O} / \mathrm{CO}_{2}$ ratios. As the metamorphic thermal regime decreased and carbonate precipitated, the aqueous-carbonic fluids became progressively impoverished in $\mathrm{CO}_{2}$ and less saline. Mixture with cooler and low salinity surface waters may have occurred at the final stages of the Montes Áureos hydrothermal system. The geotectonic setting, the structural control of the mineralization by shear zone, the hydrothermal alteration features, the time relations between the metamorphic peak and hydrothermal alteration, the gold ore mineral association and the physico-chemical characteristics of the mineralizing fluids allow the Montes Áureos gold deposit to be classified in the orogenic category, as many others that occur in deformed and metamorphosed mid-crustal blocks.
\end{abstract}

Keywords: Gurupi region, Tentugal shear zone, hydrothermal alteration, fluid inclusions, gold mineralization

Resumo O depósito de Montes Áureos localiza-se na Zona de Cisalhamento Tentugal (ZCT), de natureza compressiva/ transpressiva, onde se encontram as rochas mais deformadas do Cinturão Gurupi. A ZCT, com aproximadamente $15 \mathrm{~km}$ de largura e 100 km de extensão, tem direção geral NW-SE e marca o limite sul-sudoeste do cráton São Luís. O depósito aurífero de Montes Aureos é hospedado por rochas metavulcanossedimentares do Grupo Gurupi, de idade paleoproterozóica, que foram deformadas em regime rúptil-dúctil e mostram associações minerais típicas das fácies xisto verde e anfibolito baixo. O ouro ocorre em veios e/ou vênulas de quartzo + carbonato tardi-tectônicos de espessura milimétrica a centimétrica $(£ 2 \mathrm{~cm})$, que definem corpos lenticulares e tabulares com teores inferiores a 2 ppm subparalelos à foliação milonítica. Encontra-se associado com arsenopirita, pirita e, subordinadamente, com calcopirita, quartzo e carbonatos. As feições texturais e as relações entre as associações metamórficas e hidrotermais indicam que a mineralização ocorreu após o pico do metamorfismo, em pelo menos dois modos distintos e sucessivos: 1) grãos isolados coprecipitados com sulfetos, quartzo e carbonatos; e 2) em microfraturas da arsenopirita e pirita. O ouro teria sido transportado na forma de complexo de enxofre do tipo $\mathrm{Au}\left(\mathrm{HS}\right.$ ), - em fluidos aquo-carbônicos de baixa salinidade (equiv. a 2-8\% em peso de $\mathrm{NaCl}$ ) e temperatura $£ 450^{\circ} \mathrm{C}$. A deposição deve ter ocorrido a temperaturas entre 260 e $350^{\circ} \mathrm{C}$, com predomínio em torno de $300^{\circ} \mathrm{C}$, confirmadas pelo geotermômetro da clorita hidrotermal. A pressão é estimada em 1,3-2,8 Kbar, eqüivalente a profundidades de 4-8,5 km. No sistema hidrotermal de Montes Áureos circularam fluidos carbônicos $\left(\mathrm{CO}_{2} \pm \mathrm{CH}\right)$, aquo-carbônicos $\left(\mathrm{H}_{2} \mathrm{O}-\mathrm{NaCl}-\mathrm{CO}_{2} \pm \mathrm{CH} \pm \mathrm{Mg}\right.$ e/ou Fe $)$ e aquosos $\left(\mathrm{H}_{2} \mathrm{O}\right.$ $\mathrm{NaCl} \pm \mathrm{Mg}$ e/ou $\mathrm{Fe}$ ). Os fluidos aquo-carbônicos foram interpretados como produtos mais prováveis de reações metamórficas de desidratação e descarbonização que devem ter ocorrido principalmente nas variedades ricas em material carbonoso do pacote vulcanossedimentar, a temperaturas superiores a $500^{\circ} \mathrm{C}$. Esses fluidos, inicialmente homogêneos, foram aprisionados em cristais de quartzo ao se tornarem imiscíveis e resultaram em inclusões fluidas com diferentes razões $\mathrm{H}_{2} \mathrm{O} / \mathrm{CO}_{2}$. A diminuição da temperatura e, em decorrência, a menor produção de $\mathrm{CO}_{2}$ pelas reações de descarbonização, combinada com a precipitação dos carbonatos, tornaram os fluidos aquo-carbônicos gradativamente mais pobres em $\mathrm{CO}$ bem como mais aquosos e menos salinos. A infiltração e mistura com fluidos meteóricos não são descartadas, especialmente nos estágios finais da evolução do sistema. O contexto geotectônico regional, o controle da mineralização por zonas de cisalhamento, o tipo da alteração hidrotermal, a relação temporal entre o fluxo térmico máximo do metamorfismo e a alteração hidrotermal superimposta, a associação mineralógica do minério e as características físicoquímicas dos fluidos mineralizantes são dados que permitem classificar o depósito de Montes Áureos como do tipo orogênico semelhante aos que ocorrem em terrenos metamórficos de blocos mesocrustais intensamente deformados.

Palavras-chave: Região de gurupi, zona de cisalhamento Tentugal, alteração hidrotermal, inclusões fluidas, mineralização aurífera

1 - Curso de Pós-Graduação em Geologia e Geoquímica da UFPA, Av. Augusto Correa 1, 66075-900, Belém-PA

2 - Departamento de Geologia, Centro de Geociências, UFPA, Av. Augusto Correa 1, 66075-900, Belém-PA, email: netuno@ufpa.br 
INTRODUÇÃO A área de Montes Áureos situa-se a noroeste do estado do Maranhão, a aproximadamente $90 \mathrm{~km}$ a SSE da ponte sobre o rio Gurupi, na rodovia BR-316, dentro de uma estrutura de direção NW-SE, ao longo da qual encontram-se diversas ocorrências e antigos garimpos de ouro. Essa estrutura tem recebido várias denominações, sendo Zona de Cisalhamento Tentugal (ZCT) a mais comumente empregada.

O contexto geológico, em termos dos controles estruturais e litológicos, ambiente tectônico e atividade hidrotermal, foi favorável à mineralização de ouro, porém, até aqui, nenhum depósito de vulto foi descoberto nesse domínio, a despeito dos vários programas de exploração na área.

O exame dos testemunhos de vários furos de sondagem, que foram executados pela Mineração Chega Tudo em Montes Áureos, possibilitou observar não só a variação e as relações de contato dos tipos litológicos em profundidade, como também diferentes gerações de veios hidrotermais, tendo viabilizado o estudo daqueles constituídos por quartzo + carbonato + sulfetos $\pm \mathrm{Au}$, com ênfase nos fluidos que os formaram.

Este trabalho teve por objetivo principal caracterizar o sistema hidrotermal à época da mineralização e propor um modelo de evolução dos fluidos relacionados com o depósito aurífero de Montes Áureos.

SÍNTESE DA GEOLOGIA REGIONAL A região do Gurupi, na qual a área de Montes Áureos está inserta, pertence à província estrutural Parnaíba (Hasui et al. 1984) ou, na concepção de Hasui et al. (1993), aos blocos crustais Belém e São Luís que abrangem o nordeste do estado do Pará e o noroeste do estado do Maranhão. Essa região é compartimentada, de acordo com Pastana (1995), em três unidades geotectônicas distintas: a) o domínio cratônico; b) o domínio móvel; e c) as bacias sedimentares (Fig. 1).

O domínio cratônico ou cráton São Luís (CSL) é considerado um fragmento do cráton Oeste Africano (Hurley et al. 1967), do qual teria se separado durante a abertura do Oceano Atlântico no Mesozóico, tendo se mantido estável desde o final do ciclo Transamazônico.

O limite sul-sudoeste do CSL é marcado pela ZCT (Abreu \& Lesquer 1985), de direção NW-SE, que serviu de estrutura de articulação com o domínio móvel ou Cinturão Gurupi.

O terceiro domínio geotectônico é representado pelas bacias sedimentares que, na região, compreendem reduzidas áreas com coberturas sedimentares atribuídas ao Proterozóico e Eopaleozóico.

O domínio cratônico consiste do Grupo Aurizona, que é uma seqüência metavulcanossedimentar tipo greenstone, e da suíte Tromaí, composta por granitóides de composição tonalítica a granítica. Estes granitóides, assim como as suítes Tracuateua (corpos Tracuateua e Mirasselvas) e Rosário, foram aqui reunidos cartograficamente sob a denominação de granitóides transamazônicos, aos quais também se juntam outros que ocorrem no domínio móvel (Fig. 1).

O empilhamento estratigráfico proposto para as rochas précambrianas do domínio móvel (Pastana 1995) é, das unidades mais antigas para as mais jovens, o complexo Maracaçumé, o kinzigito Marajupema, o Grupo Gurupi, o tonalito Itamoari e o granito Maria Suprema, o que tem sido confirmado, em termos gerais, por recentes dados geocronológicos, os quais apontam idades paleoproterozóicas (2245 a $1990 \mathrm{Ma}$ ) para várias dessas unidades (Klein \& Moura 2001). O termo kinzigito usado para a unidade Marajupema é inapropriado, uma vez que sua composição mineralógica é incompatível com a fácies granulito. Como parte dos granitóides transamazônicos, foram mapeados os corpos paleoproterozóicos de Japiim, Cantão, Jonasa e Ourém (Klein \& Moura 2001). No Mesoproterozóico teria havido a intrusão do nefelina sienito de Boca Nova (Villas 1982, Lowell \& Villas 1983), enquanto o granito Ney Peixoto é a única rocha, até aqui descrita, com formação ligada ao evento Brasiliano (Palheta 2001, Villas 2001), durante o qual aquela intrusão alcalina também teria sido gnaissificada.

As feições estruturais mais marcantes da região do Gurupi estão relacionadas à evolução geotectônica do Cinturão Gurupi e, nele, à instalação da ZCT, zona esta que representa a transição da região cratônica para o domínio móvel (Hasui et al. 1984) ou, segundo F. A. Abreu (comunicação verbal), uma zona de sutura entre os blocos Belém e São Luis, que teriam colidido no Paleoproterozóico em conseqüência do fechamento do mar que os separava em ambiente típico de subducção.

No Cinturão Gurupi, foram detectados dois domínios estruturais distintos (Costa et al. 1988, Borges et al. 1994a,b), caracterizados por sistemas imbricados e transcorrentes, ambos com orientação geral NW-SE, a qual reflete transporte de massa de SW para NE. Essa movimentação ocorreu em regime tectônico compressivo obliquo ao longo de zonas de cisalhamento com características de cavalgamento (Costa et al. 1988, Borges et al. 1994a,b). O sistema imbricado deu origem a uma foliação milonítica com mergulhos de 30 a $50^{\circ} \mathrm{SW}$ e lineação de estiramento com mergulhos de 20 a $45^{\circ}$ SSW. A resistência à compressão pelo domínio cratônico fez com que o alívio das tensões passasse a ser feito por meio de um sistema transcorrente de cinemática sinistral com mergulho subvertical para SW e lineação de estiramento horizontal e suborizontal para SE ou NW, sistema este que corresponde à ZCT.

\section{O DEPÓSITO AURÍFERO DE MONTES ÁUREOS Rochas}

Hospedeiras O depósito aurífero de Montes Áureos é hospedado por rochas metavulcanossedimentares do Grupo Gurupi. O único trabalho disponível sobre este depósito refere-se a um relatório de pesquisa da Mineração Chega Tudo Ltda. (1997), a qual realizou um programa de prospecção para ouro primário incluindo mapeamento geológico de superfície, geoquímica de solo, amostragem de canal, sondagem rotativa e descrições petrográficas, quando foram identificadas rochas metassedimentares e metavulcânicas.

$\mathrm{Na}$ área do depósito, aproximadamente $85 \%$ das rochas são metassedimentares e $15 \%$ metavulcânicas. Estas últimas podem incluir variedades ultramáficas, enquanto nas rochas metassedimentares não se descarta a presença de algum material de origem piroclástica. Essas rochas foram metamorfisadas na fácies xisto verde a anfibolito baixo e deformadas em regime rúptil a rúptil-dúctil, do que resultaram diferentes formas e estilos de estruturas com variados graus de deformação. Brechas hidrotermais, em que clastos centimétricos das rochas hospedeiras estão cimentados por material quartzoso, ocorrem localmente.

ROCHAS METASSEDIMENTARES Essas rochas são dominadas por xistos, de caráter pelítico a margoso, contendo localmente leitos carbonosos (grafitosos?). Há um notável bandamento composicional responsável pela acentuada anisotropia estrutural do pacote rochoso. As principais associações minerais são: i) clorita + quartzo + carbonato + biotita; ii) clorita + quartzo + carbonato + biotita + muscovita; iii) clorita + quartzo + carbonato + muscovita; iv) clorita + quartzo + carbonato + biotita + actinolita + hornblenda; e v) clorita + quartzo + carbonato + plagioclásio + 
actinolita + hornblenda. Clorita e quartzo estão presentes em todos os tipos litológicos, enquanto os carbonatos foram descritos na maioria das amostras estudadas. Os demais constituintes são varietais. Dentre as fases acessórias, a ilmenita está sempre presente, o mesmo não acontecendo com os sulfetos (pirita, arsenopirita e calcopirita).

Os teores de quartzo variam de 10 a $50 \%$, dependendo da composição original do protólito e da intensidade da silicificação. Foram identificadas pelo menos três gerações de quartzo: i) pequenos cristais xenomórficos, normalmente fragmentados e levemente estirados segundo a foliação, os quais compõem, com os filossilicatos, opacos e às vezes anfibólios, as bandas mais foliadas ou milonitizadas; ii) agregados lenticulares de espessuras milimétricas a centimétricas dispostos, em geral, paralelamente à xistosidade, que podem ter resultado da boudinagem de veios sintectônicos ou de leitos ricos em quartzo do protólito; feições de recuperação e de recristalização são também observadas; e iii) grãos não deformados, ou deformados apenas ruptilmente, formando veios milimétricos a centimétricos, concordantes e discordantes com a foliação e interpretados com tardi a pós-tectônicos.
As proporções de clorita são também variáveis e há duas variedades. Uma é metamórfica e ocorre em agregados de finos cristais, orientados na xistosidade. É o principal constituinte das bandas lepidoblásticas formadas também por quartzo reliquiar, carbonato, fases opacas e, às vezes, anfibólio, biotita e/ou muscovita. A outra variedade, de origem hidrotermal, é representada por cristais maiores, isolados, presentes em vênulas e/ou veios de quartzo + carbonato ou como produto da alteração da biotita. Em termos composicionais, as variedades metamórfica e hidrotermal correspondem, respectivamente, ao clinocloro e à chamosita (Yamaguti 2000). O carbonato (calcita?) tem ampla distribuição e, em algumas amostras, perfaz cerca de $70 \%$ do volume da rocha. Apresenta quatro feições texturais distintas, refletindo a seqüência de eventos de deformação rúpti-dúctil ou mesmo a ação de fluidos hidrotermais: i) grãos estirados segundo a foliação milonítica, provavelmente derivados do protólito; ii) grãos presentes em quantidades limitadas em veios de quartzo boudinados ou em forma de sigmóides sintectônicos; iii) grãos em quantidades expressivas associadas ao quartzo em veios e/ou vênulas tardi ou póstectônicos; e iv) grãos em microfraturas tardias tanto na rocha

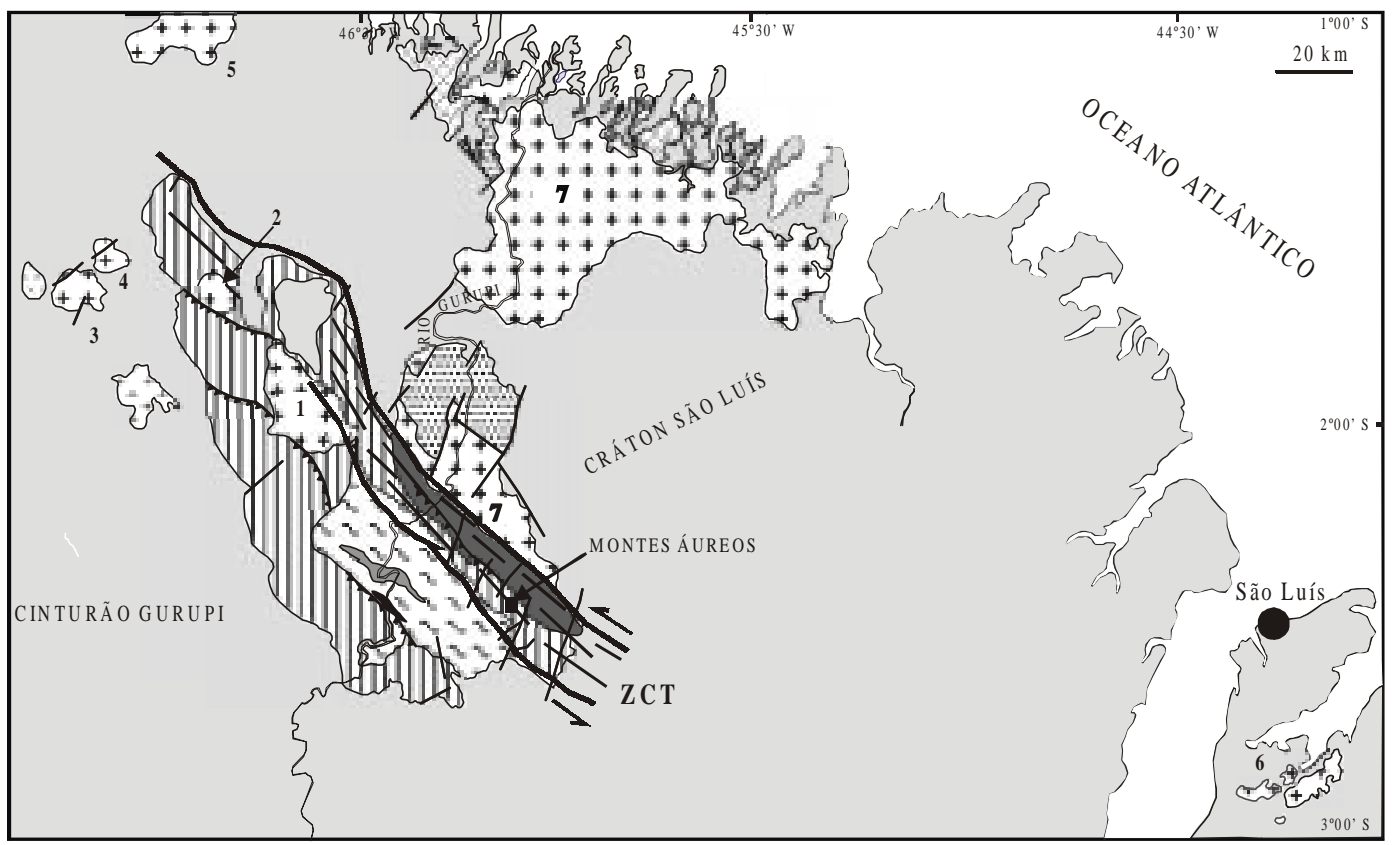

MAPA DE LOCALIZAC $\tilde{O} 0$

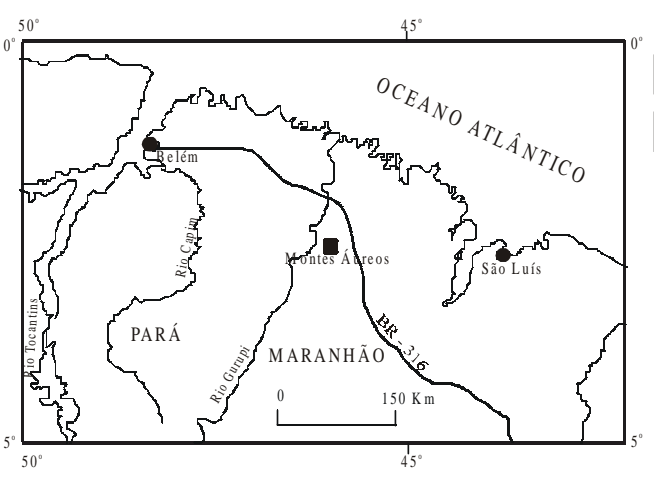

ROCHAS INTRUSIVAS

UNIDADES LITOESTRATIGRÁFICAS

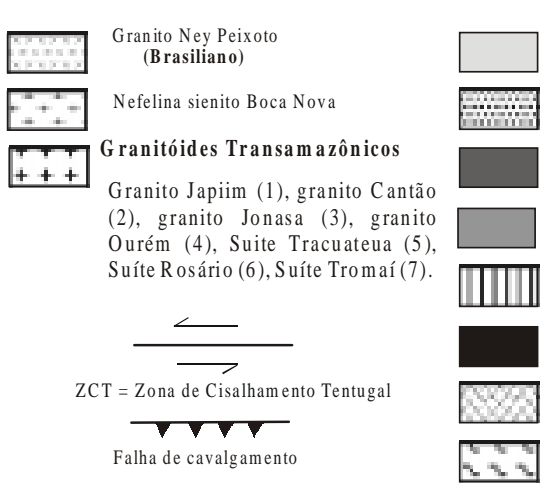

Coberturas Fanerozóicas

B acias Sedimentares

Tonalito Itamoari

Granito Maria Suprema

Grupo Gurupi

Kinzigito Marajupema

Grupo Aurizona

Complexo Maracaçumé

Figura 1 - Mapa geológico simplificado da região do Gurupi e adjacências (modificado de Klein \& Moura 2001) 
hospedeira como em sulfetos. O anfibólio ocorre em aproximadamente $25 \%$ das amostras examinadas, sendo muito abundante em algumas delas. Do ponto de vista textural, foram identificados um tipo sintectônico, em forma de cristais alongados e arranjados paralelamente à xistosidade e comumente associados ao clinocloro, e um outro distribuído semiortogonalmente à xistosidade (tarditectônico). Os cristais de anfibólio mostram um leve zoneamento, alguns com núcleos de composição ferro-edenita gradando para ferro-pargasita nas bordas, enquanto outros têm núcleos de actinolita-Mg-hornblenda e bordas de ferrotschermakita (Yamaguti 2000). Carbonato hidrotermal substitui pseudomorficamente parte desses cristais. A biotita está presente em poucas amostras com teores máximos de 5\%. Duas variedades texturais foram descritas. Uma ocorre em lamelas bem estiradas paralelas à foliação milonítica (sintectônica) em associação com clinocloro e/ou anfibólio, enquanto a outra é placóide, pouco a não deformada (tardi a póstectônica) e disposta semiortogonalmente àquela foliação. $\mathrm{O}$ feldspato ocorre, em geral, associado com rochas que contêm anfibólio, em proporções que variam de traços até $10 \%$, mas é de difícil identificação.Pode ocorrer na matriz em cristais finos ou em grãos alterados, via de regra, para carbonato. A muscovita foi observada em apenas um terço das amostras, com teores inferiores a $20 \%$, estando, em geral associada à clorita e, subordinadamente, à biotita e opacos. Nas microzonas de cisalhamento, ocorrem cristais de muscovita sintectônica transformados em finas lamelas estiradas ao longo de microfraturas. Nas microzonas menos deformadas, a muscovita ocorre em placas que truncam cristais de clorita. A sericita ocorre localmente. Os minerais acessórios compreendem rutilo, turmalina, apatita, epidoto e opacos, os últimos representados por óxidos (ilmenita>>magnetita + hematita) e sulfetos (pirita>arsenopirita + calcopirita).

ROCHAS METAVULCÂNICAS As rochas metavulcânicas, de composição riolítica a dacítica, estão menos deformadas e foliadas do que as metassedimentares e nelas o bandamento composicional é quase ausente. Trata-se de rochas cinzentas a esverdeadas, localmente amarronzadas, em que se destacam diminutos porfiroblastos de plagioclásio imersos em uma matriz composta por quartzo (20 a $30 \%)$, clorita (10 a $25 \%)$, plagioclásio(»20\%), biotita (10 a 20\%), carbonato (traços a 15\%) e, subordinadamente, por ilmenita, rutilo, epidoto, apatita e magnetita, em arranjo textural que varia de granoblástico a lepidoblástico. Evidências de alteração hidrotermal residem na substituição da biotita por clorita, plagioclásio por epidoto e ilmenita por rutilo, além de veios de quartzo + carbonato que cortam a rocha.

MododeOcorrênciae Controle da Mineralização Amineralização se procedeu preferencialmente nas rochas metassedimentares, formando corpos tabulares e lenticulares subparalelos à foliação milonítica (Fig. 2). Isto não significa dizer que tenha havido necessariamente um controle litológico, pois essas rochas, além de mais abundantes, são também mais deformadas e fraturadas do que nas rochas metavulcânicas. A heterogeneidade das rochas metassedimentares é bem caracterizada por bandamento composicional e implica maior contraste de competência, o que certamente levou a uma maior abundância de fraturas nessas rochas comparativamente às variedades metavulcânicas e, em decorrência, à criação de mais condutos para a circulação dos fluidos hidrotermais.

O ouro ocorre comumente em veios e/ou vênulas tardi-tectônicos de espessura milimétrica a centimétrica $(£ 2 \mathrm{~cm})$, contendo arsenopirita, pirita e calcopirita, além de quartzo e carbonato (Fig. 3A e 3B). A clorita também está presente e ocorre, via de regra, no contato veio/rocha hospedeira. Esses veios não mostram sinais de deformação dúctil e apresentam teores que não ultrapassam 2 ppm de Au. Houve duas fases distintas de precipitação do ouro na forma livre. Na primeira, as relações texturais indicam que o ouro é cogenético com os sulfetos (Fig. 3C e 3D), havendo grãos que apresentam contatos retos com o quartzo e arsenopirita (Fig. $3 \mathrm{E})$. A outra, mais tardia, é representada por ouro em microfraturas da arsenopirita (Fig. 3F) e pirita.

Análises parciais de partículas de ouro por microssonda eletrônica (Yamaguti 2000) revelam teores médios de 96,5\% de $\mathrm{Au}$ e $0,26 \%$ de $\mathrm{Fe}+\mathrm{S}+\mathrm{Cu}+\mathrm{Ni}+\mathrm{Sn}$. Considerando que os restantes $3,24 \%$ possam ser atribuídos à prata, que é um componente muito comum na composição do ouro, estima-se, de acordo com os dados de Chang et al. (1977), que a temperatura de formação do ouro deve ter sido inferior a $400^{\circ} \mathrm{C}$.

ALTERAÇÃO HIDROTERMAL As rochas encaixantes do depósito Montes Áureos mostram-se hidrotermalmente pouco alteradas. Os minerais de alteração são, assim, pouco abundantes, destacando-se carbonato, clorita e quartzo, subordinadamente muscovita sericitica e sulfetos. O grau de alteração hidrotermal é proporcional à intensidade da deformação das rochas hospedeiras, confirmando a relação entre a deformação e o influxo de fluidos. As relações texturais entre os minerais metamórficos e hidrotermais, bem como as feições microestruturais (microdobras e microfraturas), indicam claramente que o hidrotermalismo é posterior. A atividade hidrotermal deve, assim, ter ocorrido após o pico do metamorfismo e coincidido com a fase final da deformação.

Os veios/vênulas resultaram do preenchimento de fraturas e nelas os indícios de substituição não são marcantes. Nas rochas

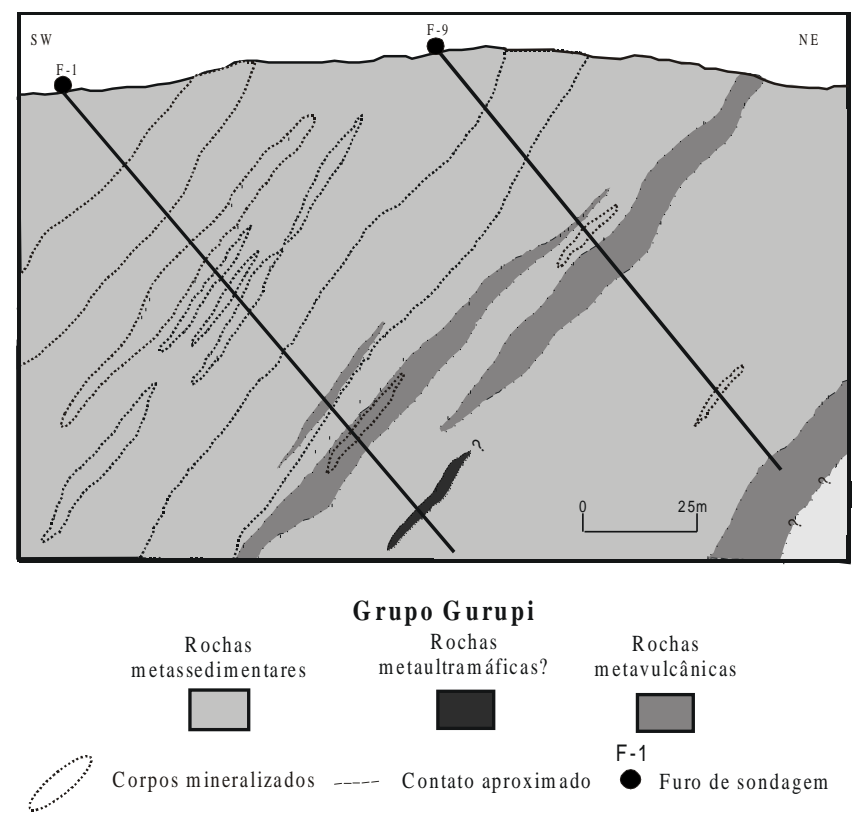

Figura 2 - Perfil esquemático interpretado a partir dos testemunhos de sondagem, mostrando a distribuição e a forma dos corpos mineralizados com ouro nas rochas do Grupo Gurupi em Montes Áureos. 

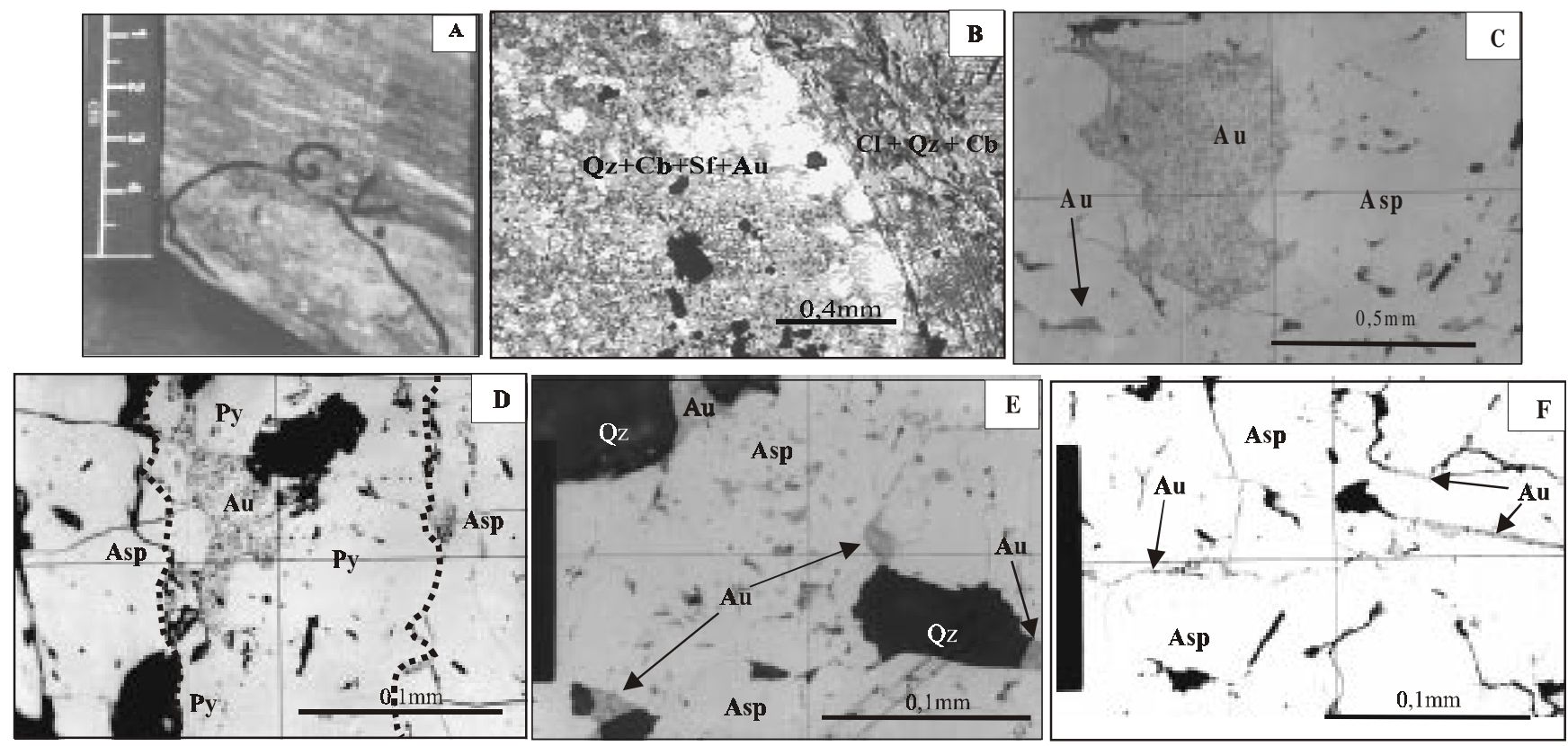

Figura 3 - Ouro na forma livre em veios de quartzo + carbonato. A) - Testemunho de sondagem de rocha metassedimentar mostrando veio de quartzo + carbonato subconcordante à foliação e mineralizado com ouro (a notação G.V. = gold vein é da Mineração Chega Tudo); B) - Fotomicrografia do veio referido em $A(Q z+C b+S f+A u)$ em contato com xisto $(C l+Q z+C b)$. $Q z=q u a r t z o ; C b=$ carbonato; $S f=$ sulfetos (tons cinzentos mais escuros); $C l=$ clorita; $C$ ) - Partícula de ouro associada com arsenopirita (Asp); D) Partícula de ouro associada com pirita (Py), arsenopirita (Asp) e minerais de ganga (cor preta); E) - Partículas de ouro em contato reto com cristais de quartzo (Qz) e de arsenopirita (Asp); e F) - Microfraturas em arsenopirita (Asp) preenchidas com ouro.

encaixantes, por outro lado, a associação mineral hidrotermal, composta por clorita, carbonato e epidoto, substitui, em parte, a associação metamórfica, principalmente os anfibólios, plagioclásio e biotita.

Foram identificados três tipos principais de alteração hidrotermal: i) carbonatação (substituição de plagioclásio e anfibólio por carbonato, veios e/ou vênulas auríferos de carbonato + quartzo associados a sulfetos e clorita, e veios de carbonato + quartzo não mineralizados de diferentes gerações); ii) silicificação (veios e/ou vênulas de quartzo + carbonato + clorita + sulfetos \pm ouro, veios de quartzo e de quartzo + carbonato estéreis); e iii) cloritização (alteração da biotita e anfibólio e veios e/ou vênulas auríferos de clorita + quartzo + carbonato).

ESTUDO DAS INCLUSÕES FLUIDAS Veios de Quartzo e de Quartzo + Carbonato Antecedendo o estudo de inclusões fluidas (IF), buscou-se definir, dentre as diferentes gerações de veios e/ou vênulas, aquelas geneticamente relacionadas com a mineralização. Os processos deformacionais, que atuaram nas rochas do Cinturão Gurupi e que culminaram com a implantação da ZCT, geraram diferentes veios e/ou vênulas de quartzo ou quartzo + carbonato, embora nem todos associados com a mineralização.

Como as partículas de ouro têm distribuição errática e foram observadas em um único veio, as características microscópicas deste veio serviram de referência para identificar outros, possivelmente de mesma linhagem genética. Assim, os veios sem ouro visível, porém textural e composicionalmente semelhantes ao veio mineralizado, foram considerados como produtos do fluido mineralizador. O objetivo foi obter um número significativo de dados para melhor caracterizar o(s) fluido(s) responsável (is) pelo transporte e deposição do ouro.

Petrografia das Inclusões Fluidas Foram estudadas cerca de 130 IF em lâminas bipolidas de cinco amostras de veios tarditectônicos contendo quartzo e carbonato. À temperatura ambiente, foram identificadas IF monofásicas, bifásicas, trifásicas e polifásicas, pertencentes a três sistemas de fluidos distintos (aquoso, carbônico e aquo-carbônico), aprisionados em cristais de quartzo (Yamaguti 2000).

As IF dos sistemas carbônico e aquo-carbônico representam $70 \%$ do total de inclusões estudadas. A distribuição espacial dessas IF permite inferir não só uma cronologia relativa para elas como também uma associação preferencial à época do aprisionamento. As inclusões carbônicas e aquo-carbônicas são mais precoces e coexistem, em geral, independentemente da classe paragenética a que pertencem. A sua coexistência com tipos aquosos é muito rara.

As IF carbônicas estão representadas por cavidades $<5 \mu \mathrm{m}$ e raramente excedem $15 \mu \mathrm{m}$, sendo monofásicas (Fig. 4A e 4B) e bifásicas (Fig. 4C) de origens primária, pseudosecundária e secundária. Os três tipos paragenéticos normalmente coexistem em um mesmo cristal hospedeiro, o que sugere a presença do $\mathrm{CO}_{2}$ durante o crescimento dos cristais e também nos fluidos relacionados aos eventos de deformação subseqüentes. As IF bifásicas primárias ocorrem isoladas ou agrupadas aleatoriamente e mostram grau de preenchimento que varia de 0,6 a 0,9 .

As IF aquo-carbônicas são bifásicas (Fig. 4A, 4B, 4C e 4E), trifásicas não saturadas (Fig. 4E), trifásicas saturadas (Fig. 4B) e polifásicas, as últimas com um ou dois minerais de saturação, sendo um a halita e o outro provavelmente um carbonato. As inclu- 
sões aquo-carbônicas constituem uma população extremamente heterogênea em termos da razão $\mathrm{H}_{2} \mathrm{O} / \mathrm{CO}_{2}$. Há, assim, lado a lado, inclusões muito ricas e muito pobres em $\mathrm{CO}_{2}$ (Fig. 4D), as quais podem ser muitas vezes confundidas, respectivamente, com as dos sistemas aquoso e carbônico. A associação espacial das IF dos sistemas carbônico e aquo-carbônico é comum e independe dos tipos paragenéticos identificados (Fig. 4A, 4B e 4C).

A distribuição da grande maioria das inclusões aquosas sugere aprisionamento em planos de microfraturas estruturados de forma distinta das que aprisionam as IF secundárias carbônicas e aquocarbônicas. As IF aquosas são monofásicas e bifásicas. As primeiras, em geral inadequadas para os testes microtermométricos, mostram, normalmente, formas indefinidas e fortes indícios de estrangulamento. As IF bifásicas comumente têm grau de preenchimento entre 0,6 e 0,9 e dimensões que variam de 5 a $35 \mathrm{~mm}$. As IF bifásicas maiores, da mesma maneira que as monofásicas, também apresentam sinais de estrangulamento.

Microtermometria SISTEMA $\mathrm{CO}_{2} \pm \mathrm{CH}_{4}$ Durante o resfriamento dos tipos monofásicos, ocorre inicialmente a separação das fases líquida e vapor a temperatura que varia desde próximo a do ambiente até $9^{\circ} \mathrm{C}$. No reaquecimento, após o congelamento total das IF, a primeira mudança de fase corresponde à fusão do $\mathrm{CO}_{2}$ sólido $\left(\mathrm{Tf}_{\mathrm{CO} 2}\right)$, que se dá na faixa de $-58,5 \mathrm{a}-57,2^{\circ} \mathrm{C}$ com moda em torno de $-58,2^{\circ} \mathrm{C}$ (Fig. $5 \mathrm{~B}$ ). A despeito da falta de análises por espectrometria Raman, considera-se o metano como o mais provável contaminante e responsável pela depressão da $\mathrm{Tf}_{\mathrm{CO} 2}$.

A homogeneização da fase carbônica $\left(\mathrm{Th}_{\mathrm{CO} 2}\right)$ nas IF monofásicas e bifásicas acontece sempre na fase líquida, dentro de um amplo intervalo $\left(4,4\right.$ a $\left.25,8^{\circ} \mathrm{C}\right)$ nas monofásicas e de um intervalo mais estreito $\left(22,2\right.$ a $\left.29,3^{\circ} \mathrm{C}\right)$ nas bifásicas. Como um todo, as IF carbônicas mostram as mais freqüentes $\mathrm{Tf}_{\mathrm{CO} 2}$ entre 20 e $29,3^{\circ} \mathrm{C}$ (Fig. 5A) e, neste intervalo, a densidade dos fluidos varia de 0,60 a $0,78 \mathrm{~g} / \mathrm{cm}^{3}$.

Com base na temperatura de homogeneização e curvas de densidade calculadas para as IF monofásicas e bifásicas, estimam-se concentrações de $\mathrm{CH}_{4}$ na fase carbônica (Swanenberg, 1979) que variam de $\mathrm{a} 0$ a $6 \%$ molar.

SISTEMA $\mathrm{H}_{2} \mathrm{O}-\mathrm{CO}_{2} \pm \mathrm{CH}_{4}-\mathrm{NaCl} \pm \mathrm{MgCl}_{2}$ elou $\mathrm{FeCl}_{2}$ As $\mathrm{Tf}_{\mathrm{CO} 2}$ acusam valores abaixo do ponto tríplice do $\mathrm{CO}_{2}\left(-56,6^{\circ} \mathrm{C}\right)$, sendo de -58 a $-57,7^{\circ} \mathrm{C}$ nas IF bifásicas, de $-58,4$ a $-57,1^{\circ} \mathrm{C}$ nas IF trifásicas e próximo de $-58,2^{\circ} \mathrm{C}$ em algumas IF polifásicas (Fig. 6A). À semelhança das IF carbônicas, a depressão do ponto tríplice é atribuída à presença de $\mathrm{CH}_{4}$

As temperaturas eutéticas da fase aquosa registram valores entre $-34,6 \mathrm{e}-25^{\circ} \mathrm{C}$ nas IF bifásicas, $-37,3 \mathrm{e}-24,9^{\circ} \mathrm{C}$ nas IF trifásicas e$38,1 \mathrm{e}-32^{\circ} \mathrm{C}$ nas IF polifásicas com valores mais freqüentes nas faixas de $-38 \mathrm{a}-32^{\circ} \mathrm{Ce}-30 \mathrm{a}-28^{\circ} \mathrm{C}$ (Fig. 6B). Essas temperaturas situam-se bem abaixo do ponto eutético do sistema $\mathrm{H}_{2} \mathrm{O}-\mathrm{NaCl}$ ($20,8^{\circ} \mathrm{C}$ ), o que implica a presença de outros cátions em solução, os mais prováveis sendo $\mathrm{Mg}^{+2} \mathrm{e} \mathrm{Fe}^{+2}$. Embora de difícil identificação, a hidrohalita foi observada em duas inclusões polifásicas, com a fusão $\left(\mathrm{Tf}_{\text {hid }}\right)$ tendo ocorrido a $-1,5 \mathrm{e}-5^{\circ} \mathrm{C}$ (Tab. 1). Temperaturas eutéticas entre $-38,1$ e $-32^{\circ} \mathrm{C}$ e $\mathrm{Tf}_{\text {hid. }}$ entre $-7,5 \mathrm{e}-1,5^{\circ} \mathrm{C}$ podem indicar, segundo Davis et al. (1990), concentrações em torno de 0,9 a $1,5 \mathrm{~mol}$ de $\mathrm{MgCl}_{2}$ quando o hidrato deste cloreto estiver na sua forma estável.

As temperaturas de fusão gelo $\left(\mathrm{Tf}_{\mathrm{g}}\right.$ ) foram usadas para estimar a salinidade apenas de IF aquo-carbồnicas com altas razões $\mathrm{H}_{2} \mathrm{O}$ / $\mathrm{CO}_{2}$, nas quais a formação de clatratos deve ter sido inexpressiva e, portanto, impraticável de ser observada. Em inclusões com menores razões $\mathrm{H}_{2} \mathrm{O} / \mathrm{CO}_{2}$ os clatratos visivelmente se formam e as salinidades foram calculadas com base na temperatura de fusão destes hidratos $\left(\mathrm{Tf}_{\mathrm{cla}}\right)$.

As $\mathrm{Tf}_{\mathrm{g}}$ variam de $-11 \mathrm{a}-1,7^{\circ} \mathrm{C}$ nas IF bifásicas e de $-12 \mathrm{a}-2^{\circ} \mathrm{C}$ nas IF trifásicas. As $\mathrm{Tf}_{\text {cla }}$ foram determinadas nas IF trifásicas, cobrindo o intervalo de 3,6 a $8,9^{\circ} \mathrm{C}$, e em apenas uma IF bifásica com baixa razão $\mathrm{H}_{2} \mathrm{O} / \mathrm{CO}_{2}$, registrando-se $2,2^{\circ} \mathrm{C}$ (Fig. $6 \mathrm{C}$ ). Nos cálculos da salinidade com base em $\mathrm{Tf}_{\mathrm{g}}$ e $\mathrm{Tf}_{\text {cla }}$ foram usadas, respectivamente, as equações de Bodnar (apud Goldstein \& Reynolds 1994) e de Bozzo e colaboradores (apud Parry 1986), as quais acusam valores eqüivalentes a \% em peso de $\mathrm{NaCl}$ de 2,9 até 14,9 nas IF bifásicas e de 2,2 até 11,1 nas IF trifásicas. No conjunto de If bifásicas e trifásicas, a salinidade mais freqüente situa-se no intervalo eqüivalente a 2,2-8\% em peso de $\mathrm{NaCl}$ (Fig. 6D). Entretanto, como não se dispõe de dados sobre os coeficientes de partição do $\mathrm{CO}_{2}$ e do $\mathrm{CH}_{4}$ nos clatratos, os valores de salinidade observados com base em $\mathrm{Tf}_{\text {cla }}$ podem conter erros significativos (Seitz \& Pasteris 1990).

Quanto à temperatura de homogeneização da fase carbônica, constatou-se que, no estado gasoso, homogeneízam apenas as IF bifásicas com baixas razões $\mathrm{H}_{2} \mathrm{O} / \mathrm{CO}_{2}$, obtendo-se valores no intervalo de $8,2 \mathrm{a} 25^{\circ} \mathrm{C}$. Em IF com altas razões $\mathrm{H}_{2} \mathrm{O} / \mathrm{CO}_{2}$, o pequeno volume de $\mathrm{CO}_{2}$ não permite observar, com segurança, em que estado ocorre a homogeneização. Nas IF trifásicas, a homogeneização acontece sempre no estado líquido entre 13 e $30^{\circ} \mathrm{C}$ (Fig. 6E). Considerando apenas aquelas nas quais foi possível medir $\mathrm{Tf}_{\text {cla }}$, a densidade varia de $0,69 \mathrm{a} 0,89 \mathrm{~g} / \mathrm{cm}^{3}$.

A homogeneização total ( $\mathrm{Th}$ ) das inclusões bifásicas com baixas e altas razões $\mathrm{H}_{2} \mathrm{O} / \mathrm{CO}_{2}$ ocorre, respectivamente, nos estados vapor e líquido. Nas IF bifásicas e trifásicas registram-se, respectivamente, intervalos de 231 a $296^{\circ} \mathrm{Ce} \mathrm{de} 263$ a $392^{\circ} \mathrm{C}$ (Fig. 6F). Nas IF polifásicas com um mineral de saturação foram obtidas apenas duas temperaturas de homogeneização parcial $\left(\mathrm{Th}_{\mathrm{p}}\right)$ fornecidas pela dissolução da halita e medidas a $372^{\circ} \mathrm{C}$ e $412^{\circ} \mathrm{C}$, o que corresponde a salinidade eqüivalente a aproximadamente $42-43 \%$ em peso de $\mathrm{NaCl}$, segundo a curva de solubilidade da halita em soluções aquosas (Shepherd et al. 1985). Quase a totalidade dessas inclusões crepita a temperaturas em torno de $450^{\circ} \mathrm{C}$ sem que ocorra a homogeneização total das fases aquosa e carbônica. Estes dados podem ser significativos, mas também podem apontar para aprisionamento de fluidos em condições heterogêneas, o que é previsível após a separação de fases (Roedder 1984).

SISTEMA $\mathrm{H}_{2} \mathrm{O}-\mathrm{NaCl} \pm \mathrm{MgCl}_{2}$ elou $\mathrm{FeCl}_{2}$ Os testes de resfriamento em IF monofásicas e bifásicas acusam temperaturas $\mathrm{Tf}_{\mathrm{g}}$ entre -6 e $0^{\circ} \mathrm{C}$, sendo mais freqüente o intervalo de -4 a $0^{\circ} \mathrm{C}$. Estas temperaturas correspondem à salinidade eqüivalente $\mathrm{a} 6,5 \mathrm{a}$ $0 \%$ em peso de $\mathrm{NaCl}$ (Fig. 5E).

A temperatura da primeira fusão $\left(\mathrm{T}_{\mathrm{e}}\right)$ das IF monofásicas não pôde ser medida, talvez pela baixa salinidade do fluido. Porém nas IF bifásicas elas variam, na maioria, de $-36,6 \mathrm{a}-18^{\circ} \mathrm{C}$, com discreto predomínio dos intervalos de $-36,6 \mathrm{a}-33,6^{\circ} \mathrm{C}$ e de $-27,6 \mathrm{a}-24,6^{\circ} \mathrm{C}$ (Fig. 5C). Estas temperaturas, semelhantemente às que foram medidas na fase aquosa das IF aquo-carbônicas, devem indicar a presença de $\mathrm{MgCl}_{2} \mathrm{e} / \mathrm{ou} \mathrm{FeCl}_{2}$, sobretudo nas IF com T menores. Com relação ao $\mathrm{MgCl}_{2}$, a variação pode ser também atribuída ao comportamento metaestável do bischofito (Davis et al. 1990).

A homogeneização total ocorre sempre no estado líquido, a temperaturas entre 85 e $189^{\circ} \mathrm{C}$, com maior incidência daquelas no intervalo de 120 a $160^{\circ} \mathrm{C}$ (Fig. 5F). A densidade calculada indica 

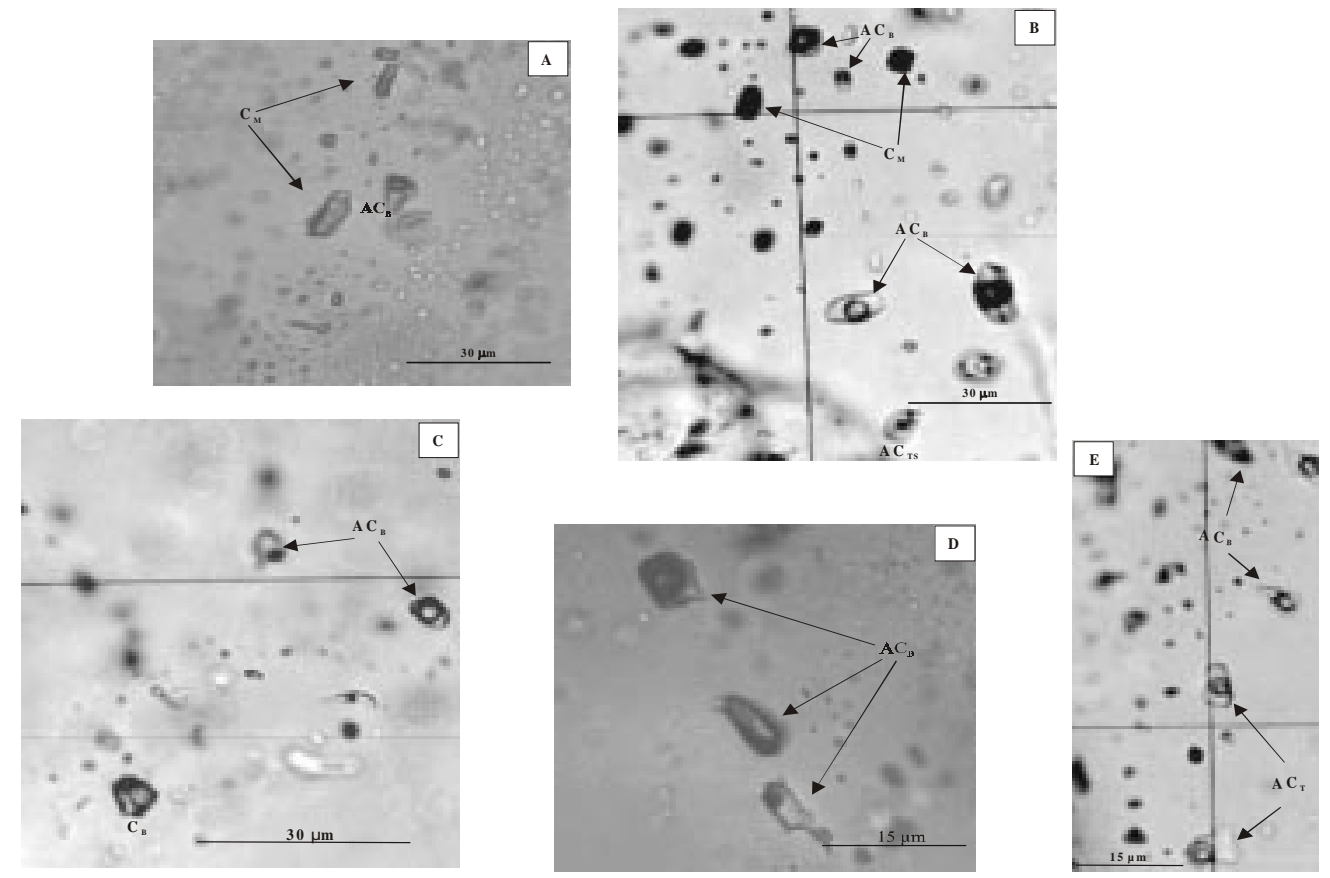

Figura 4 - Fotomicrografias de inclusões fluidas (IF) em cristais de quartzo de veios. A) - IF aquo-carbônicas bifásicas (AC ${ }_{B}$ ) associadas com IF carbônicas monofásicas $\left.\left(C_{M}\right) ; B\right)$ - IF carbônicas monofásicas $\left(C_{M}\right)$ associadas com aquo-carbônicas bifásicas $\left(A C_{B}\right)$ e trifásicas saturadas $\left.\left(A C_{T S}\right) ; C\right)$ - IF aquo-carbônicas bifásicas $\left(A C_{B}\right)$ associadas com carbônicas bifásicas $\left.\left(C_{B}\right) ; D\right)$ - IF aquocarbônicas bifásicas $\left(A C_{B}\right)$ primárias com diferentes razões $\mathrm{H}_{2} \mathrm{O} / \mathrm{CO}_{2}$; e E) - IF aquo-carbônicas bifásicas $\left(A C_{B}\right)$ e trifásicas $\left(A C_{T}\right)$ associadas.
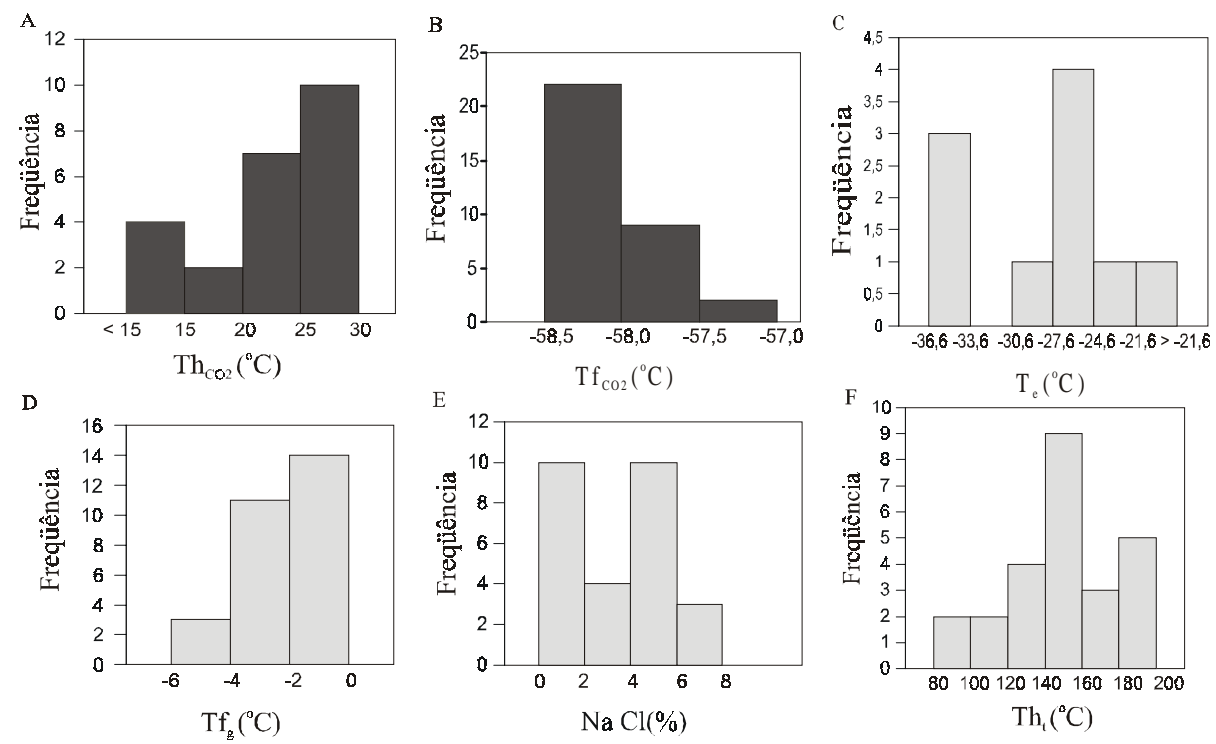

Figura 5 - Histogramas de freqüência de dados microtermométricos dos sistemas carbônico (A e B) e aquoso (C, D, E e F). A) - Temperatura de homogeneização do $\left.\mathrm{CO}_{2}\left(\mathrm{Th}_{\mathrm{CO} 2}\right) ; \mathrm{B}\right)$ - Temperatura de fusão do $\left.\mathrm{CO}_{2}\left(\mathrm{Tf}_{\mathrm{CO} 2}\right) ; \mathrm{C}\right)$ - Temperatura eutética $\left(\mathrm{T}_{e}\right)$ referente às $I F$ aquosas bifásicas; D) - Temperatura de fusão do gelo $\left(T f_{g}\right)$ referente às IF aquosas bifásicas e monofásicas; E) - Salinidade referente às IF aquosas bifásicas e monofásicas; e F) - Temperatura de homogeneização total (Th) das IF aquosas bifásicas.

pouca variação $\left(0,89\right.$ e $\left.0,99 \mathrm{~g} / \mathrm{cm}^{3}\right)$, os valores mais comuns situando-se entre 0,92 e $0,95 \mathrm{~g} / \mathrm{cm}^{3}$.

Os resultados de análises microtermométricas de todas as IF estudadas encontram-se reunidos da Tabela 1.
CONDIÇÕES DE APRISIONAMENTO E EVOLUÇÃODOS FLUIDOS HIDROTERMAIS As Th $\mathrm{e}$ as densidades dos fluidos carbônicos/aquo-carbônicos e aquosos de Montes Áureos indicam que eles foram aprisionados em condições de temperatu- 

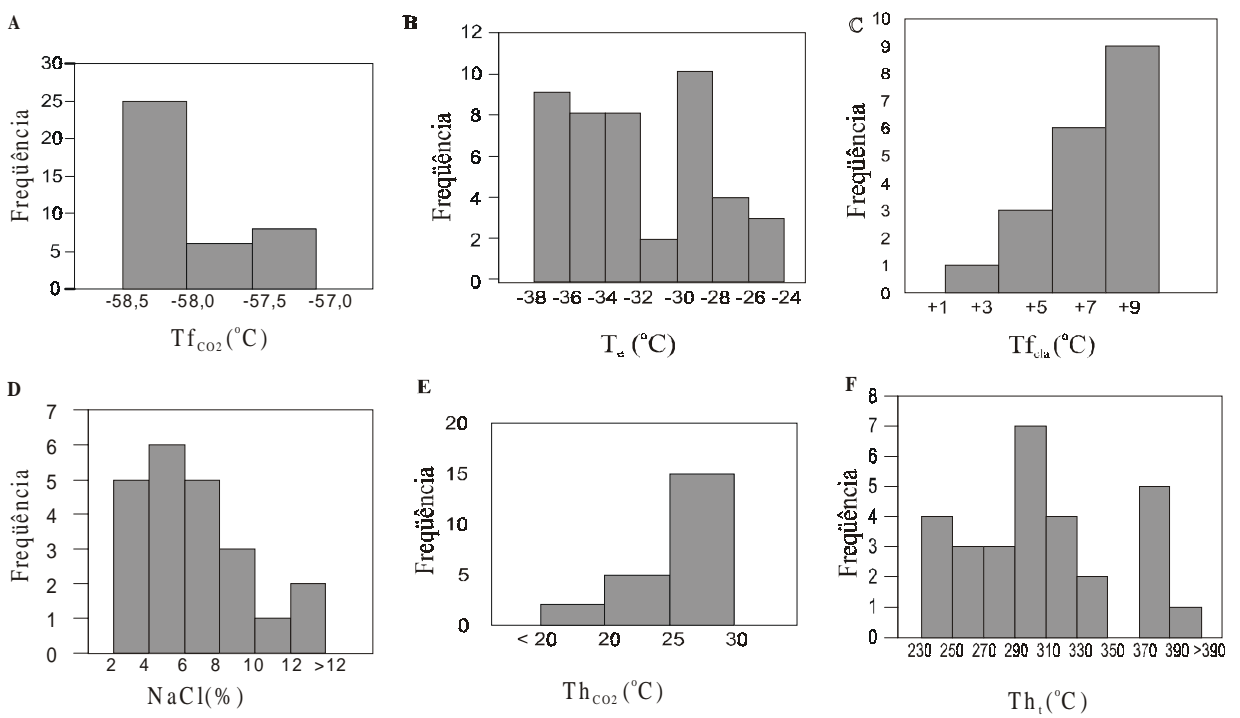

Figura 6 - Histogramas de freqüência relativos às IF aquo-carbônicas. A) - Temperaturas de fusão do $\mathrm{CO}_{2}\left(\mathrm{Tf}_{\mathrm{CO} 2}\right)$; $\left.\mathrm{B}\right)$ Temperaturas eutéticas $\left(T_{e}\right)$ da fase aquosa; $C$ ) - Temperaturas de fusão dos clatratos $\left(T f_{\text {cla }}\right)$; D) - Salinidade das IF bifásicas e trifásicas não saturadas estimadas com base em $T f_{\text {cla }}$ e $\left.T f_{g} ; E\right)$ - Temperatura de homogeneização da fase carbônica (Th ${ }_{\mathrm{CO} 2}$ ) presente nas IF trifásicas; e F) - Temperatura de homogeneização total $\left(T_{t}\right)$ das IF bifásicas e trifásicas.

ra e pressão diferentes e sinalizam para uma evolução térmica regressiva com os últimos estágios sendo dominados pelos fluidos aquosos. Ademais, feições petrográficas e $\mathrm{Tf}_{\mathrm{CO} 2}$ igualmente deprimidas por $\mathrm{CH}_{4}$ (?) sugerem que os fluidos carbônicos e aquocarbônicos foram contemporâneos e provavelmente cogenéticos.

A maioria das IF do sistema aquo-carbônico mostra um estreito intervalo de variação de $\mathrm{Th}_{\mathrm{CO} 2}\left(26 \mathrm{a} 30^{\circ} \mathrm{C}\right)$, com discreto aumento, exceto três pontos, em direção aos maiores valores de $\mathrm{Th}_{\mathrm{t}}$ (Fig. 7A). Isto é indicativo de que elas foram aprisionadas a diferentes temperaturas e/ou a partir de fluidos com razões $\mathrm{H}_{2} \mathrm{O} / \mathrm{CO}_{2}$ variadas. As diferentes razões são uma característica comum dessas IF e se refletem na correlação negativa entre $\mathrm{Th}_{t}$ e $\mathrm{CO}_{2}$, em que as temperaturas mais elevadas correspondem aos fluidos mais pobres em $\mathrm{CO}_{2}$ (Fig. 7B), em consonância com modelos propostos para o sistema $\mathrm{CO}_{2}-\mathrm{H}_{2} \mathrm{O}$ (Diamond 2001). Trata-se, muito provavelmente, do resultado da imiscibilidade de um fluido inicialmente homogêneo com o aprisionamento das IF ocorrendo após a separação das fases. $\mathrm{O}$ amplo intervalo de variacão de $\mathrm{Th}$, no entanto, pode significar que o aprisionamento ocorreu, pelo menos em parte, em condições próprias de um sistema heterogêneo.

As Th das IF aquo-carbônicas $\left(231 \mathrm{a}>450^{\circ} \mathrm{C}\right)$ e aquosas $(85 \mathrm{a}$ $189^{\circ} \mathrm{C}$ ) marcam distintamente os regimes termais de circulação dos fluidos, ficando evidente que os fluidos aquosos, além de posteriores, foram aprisionados a temperaturas mais baixas. A escassez de fluidos aquo-carbônicos abaixo de cerca de $200^{\circ} \mathrm{C}$ pode significar que grande parte do $\mathrm{CO}_{2}$ foi consumida com a produção de carbonato hidrotermal e/ou que o regime térmico do metamorfismo já não era suficientemente forte para provocar descarbonização, passando, então, a prevalecer as reações de desidratação. É possível também que, por terem menor densidade que as IF aquosas, as IF aquo-carbônicas mais ricas em $\mathrm{CO}_{2}$ tenham, com o passar do tempo, escapado mais facilmente do ambiente em que a mineralização ocorria. Por seu turno, as temperaturas em torno de $85^{\circ} \mathrm{C}$, a diferente composição e as baixas salinidades devem registrar os estágios finais da circulação dos fluidos aquosos, já com gran- de contribuição de águas mais superficiais.

Os intervalos de variação da densidade dos fluidos carbônicos $\left(0,60\right.$ a $\left.0,90 \mathrm{~g} / \mathrm{cm}^{3}\right)$ e aquo-carbônicos de $\left(0,69\right.$ a $\left.0,89 \mathrm{~g} / \mathrm{cm}^{3}\right)$ são comparáveis e podem refletir, além de diferenças composicionais, mudanças na temperatura e pressão de aprisionamento. A ocorrência de brechas de provável origem hidráulica em Montes Áureos (Yamaguti 2000) pode ser uma evidência de que, localmente, as pressões confinantes foram suplantadas pelas pressões dos fluidos $\left(\mathrm{P}_{\mathrm{F}}\right)$. Além disso, no Cinturão Gurupi falhas são estruturas comuns (Fig. 1) e algumas delas podem ter atuado como válvulas de escape de fluidos (Sibson et al. 1988), justificando, em parte, a variação de pressão.

Estimativas da pressão de aprisionamento dos fluidos aquocarbônicos foram feitas com base nas isócoras relativas ao intervalo mais representativo da densidade, com o que foram obtidas pressões entre 1,3 e 2,8 kbar, correspondendo a 4-8,5 km de carga litostática (Fig. 8). As temperaturas de 296 a $302^{\circ} \mathrm{C}$ foram calculadas pelo geotermômetro da clorita (Cathelineau \& Nieva 1985, Cathelineau 1988), a partir de dados químicos da clorita hidrotermal de Montes Áureos que revelam, após correção proposta por Zang \& Fyfe (1995), valores de alumínio tetraédrico $\left(\mathrm{Al}^{\mathrm{iv}}\right)$ entre 2,62 e 2,68 afu (Yamaguti 2000). Àquelas profundidades, a imiscibilidade de fluidos aquo-carbônicos poderia ser inibida, mas experimentos demonstram que a superfície do solvus se expande com o aumento da temperatura e da concentração de $\mathrm{NaCl}$, permitindo a separação das fases mesmo a temperaturas superiores a $600^{\circ} \mathrm{C}$ (Takenouchi \& Kennedy 1965; Bowers \& Helgeson 1983; Shepherd et al. 1985; Hollister 1990). O intervalo termal de 296 a $302^{\circ} \mathrm{C}$ é consistente com a não observação de pirrotita nas rochas hidrotermalizadas de Montes Áureos a qual, para ser formada a 2 kbar, requer temperatura superior a $320^{\circ} \mathrm{C}$, conforme as relações de fases do sistema Fe-O-S (Mikucki 1998). Temperaturas abaixo de $320^{\circ} \mathrm{C}$ favorecem, por outro lado, a formação de magnetita em equilíbrio com pirita, o que é observado, ainda que localmente, em Montes Áureos (Yamaguti 2000). 
Tabela 1 - Principais características microtermométricas de inclusões fluidas aprisionadas em cristais de quartzo do sistema hidrotermal de Montes Áureos (temperatura em ${ }^{\circ} \mathrm{C}$ ).

\begin{tabular}{|c|c|c|c|c|c|c|c|c|c|c|c|c|c|}
\hline SISTEMA & $\begin{array}{c}\text { TIPOS DE } \\
\text { INCLUSÕES }\end{array}$ & d & $\mathrm{F}$ & $\mathrm{T}_{\mathrm{e}}$ & $\mathrm{Tf}_{\mathrm{g}}$ & $\mathrm{Tf}_{\text {hid. }}$ & $\mathrm{Tf}_{\text {cla. }}$ & $\mathrm{Tf}_{\mathrm{co} 2}$ & $\mathrm{Th}_{\mathrm{co} 2}$ & $\mathrm{Th}_{\mathrm{P}}$ & $\mathrm{Th}_{\mathrm{t}}$ & $\mathrm{NaCl}$ & D \\
\hline \multirow[b]{2}{*}{$\mathrm{H}_{2} \mathrm{O}-\mathrm{NaCl}$} & $\begin{array}{c}\text { Aquosa monofásica } \\
\left(\mathrm{L}_{1}\right)\end{array}$ & $\begin{array}{c}5 \times 12 \\
a \\
9 \times 20 \\
\end{array}$ & 1 & & $-0,9$ & & & & & & & 1,57 & $\begin{array}{c}0,89 \\
\mathrm{a} \\
0,99 \\
\end{array}$ \\
\hline & $\begin{array}{l}\text { Aquosa bifásica } \\
\qquad\left(\mathrm{L}_{1}+\mathrm{V}_{1}\right)\end{array}$ & $\begin{array}{c}5 \times 5 \\
a \\
35 \times 35 \\
\end{array}$ & $\begin{array}{c}0,6 \\
\mathrm{a} \\
0,9\end{array}$ & $\begin{array}{c}-36,6 \\
\mathrm{a} \\
-8,0 \\
\end{array}$ & $\begin{array}{c}-6,0 \\
a \\
0 \\
\end{array}$ & & & & & & $\begin{array}{c}+84,5 \\
a \\
+188,9 \\
\end{array}$ & $\begin{array}{c}0 \\
\mathrm{a} \\
9,21\end{array}$ & \\
\hline \multirow[t]{2}{*}{$\mathrm{CO}_{2} \pm \mathrm{CH}_{4}$} & $\begin{array}{l}\text { Carbônica monofásica } \\
\qquad\left(\mathrm{V}_{2}\right)\end{array}$ & $\begin{array}{c}4 \times 5 \\
a \\
10 \times 12 \\
\end{array}$ & 0 & & & & & $\begin{array}{c}-58,0 \\
\mathrm{a} \\
-57,5 \\
\end{array}$ & $\begin{array}{c}+4,4 \\
\mathrm{a} \\
+25,8 \\
\end{array}$ & & & & \multirow{2}{*}{$\begin{array}{c}0,60 \\
\mathrm{a} \\
0,90\end{array}$} \\
\hline & $\begin{array}{l}\text { Carbônica bifásica } \\
\qquad\left(\mathrm{L}_{2}+\mathrm{V}_{2}\right)\end{array}$ & $\begin{array}{c}5 \times 5 \\
a \\
15 \times 17 \\
\end{array}$ & $\begin{array}{c}0,60 \\
\mathrm{a} \\
0,90\end{array}$ & & & & & $\begin{array}{c}-58,5 \\
\mathrm{a} \\
-57,2 \\
\end{array}$ & $\begin{array}{c}+22,2 \\
a \\
+29,8 \\
\end{array}$ & & & & \\
\hline \multirow{4}{*}{$\begin{array}{l}\mathrm{NaCl}-\mathrm{H}_{2} \mathrm{O}- \\
\mathrm{CO}_{2} \pm \mathrm{CH}_{4}\end{array}$} & $\begin{array}{l}\text { Aquo-carbônica bifásica } \\
\qquad\left(\mathrm{L}_{1}+\mathrm{L}_{2}\right)\end{array}$ & $\begin{array}{c}6 \times 12 \\
a \\
12 \times 17\end{array}$ & $\begin{array}{c}0,10 \\
\mathrm{a} \\
0,80\end{array}$ & $\begin{array}{c}-34,0 \\
\text { a } \\
-25,0\end{array}$ & $\begin{array}{c}-11,0 \\
a \\
-1,70\end{array}$ & & $+2,2$ & $\begin{array}{c}-58,0 \\
a \\
-57,7\end{array}$ & $\begin{array}{c}+8,2 \\
\mathrm{a} \\
+25,0\end{array}$ & & $\begin{array}{c}+231,3 \\
a \\
+295,8\end{array}$ & $\begin{array}{c}2,90 \\
a \\
14,97\end{array}$ & \multirow{4}{*}{$\begin{array}{c}0,69 \\
\text { a } \\
0,89\end{array}$} \\
\hline & $\begin{array}{l}\text { Aquo-carbônica trifásica } \\
\left(\mathrm{L}_{1}+\mathrm{L}_{2}+\mathrm{V}_{2}\right)\end{array}$ & $\begin{array}{c}5 \times 5 \\
a \\
17 \times 17\end{array}$ & $\begin{array}{c}0,50 \\
\mathrm{a} \\
0,90\end{array}$ & $\begin{array}{c}-37,3 \\
a \\
-24,9\end{array}$ & $\begin{array}{c}-12,0 \\
a \\
-2,0\end{array}$ & & $\begin{array}{c}+3,6 \\
\mathrm{a} \\
+8,9\end{array}$ & $\begin{array}{c}-58,4 \\
\text { a } \\
-57,1\end{array}$ & $\begin{array}{c}+13,1 \\
a \\
+28,8\end{array}$ & & $\begin{array}{r}+263,0 \\
a \\
+391,8\end{array}$ & $\begin{array}{c}2,20 \\
a \\
11,15\end{array}$ & \\
\hline & $\begin{array}{c}\text { Aquo-carbônica polifásica } \\
\left(\mathrm{L}_{1}+\mathrm{L}_{2}+\mathrm{V}_{2}+\mathrm{S}_{1}\right)\end{array}$ & $\begin{array}{c}5 \times 7 \\
a \\
5 \times 15\end{array}$ & $\begin{array}{c}0,60 \\
\mathrm{a} \\
0,90\end{array}$ & $\begin{array}{c}-38,1 \\
\mathrm{a} \\
-32,0\end{array}$ & & $\begin{array}{c}-5,0 \\
\mathrm{a} \\
-1,5 \\
\end{array}$ & & $-58,2$ & $+15,4$ & $\begin{array}{c}+372,1 \\
a \\
+412,2\end{array}$ & $>450,0$ & & \\
\hline & $\begin{array}{l}\text { Aquo-carbônica polifásica } \\
\qquad\left(\mathrm{L}_{1}+\mathrm{L}_{2}+\mathrm{V}_{2}+\mathrm{S}_{1}+\mathrm{S}_{2}\right)\end{array}$ & $\begin{array}{c}8 \times 8 \\
a \\
7 \times 20\end{array}$ & & $\begin{array}{c}-26,0 \\
a \\
-24,6\end{array}$ & & & & & & & & & \\
\hline
\end{tabular}

$\mathrm{d}=$ Dimensões $(\mu \mathrm{m}) ; \mathrm{D}=$ Densidade $\left(\mathrm{g} / \mathrm{cm}^{3}\right) ; \mathrm{F}=\mathrm{Grau}$ de preenchimento $\mathrm{L}_{1}=\mathrm{H}_{2} \mathrm{O}$ líquido; $\mathrm{L}_{2}=\mathrm{CO}_{2}$ líquido; $\mathrm{NaCl}=\mathrm{Salinidade}(\mathrm{eq} . \mathrm{a} \%$ em peso de

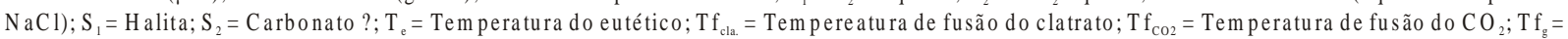

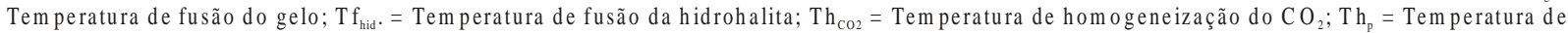
hom ogeneização parcial; $\mathrm{Th}_{\mathrm{t}}=\mathrm{Tem}$ peratura de hom ogeneização total; $\mathrm{V}_{1}=\mathrm{H}_{2} \mathrm{O}$ vapor; $\mathrm{V}_{2}=\mathrm{CO}_{2}$ vapor.

A origem dos fluidos ainda é muito especulativa. É possível que os fluidos carbônicos e aquo-carbônicos que circularam na área de Montes Áureos à época da mineralização sejam oriundos das reações de desidratação e descarbonização a que foram submetidas as rochas vulcanossedimentares durante o metamorfismo. A abundância de $\mathrm{CO}_{2}$ nesses fluidos certamente requer um reservatório rico em carbono, como parecem ter sido as sequiências vulcanossedimentares pré-cambrianas (Condie 1981). Xistos carbonosos, com até $0,5 \%$ de carbono, são comuns na área contigua de Chega Tudo (Villas, dado inédito) e bem poderiam ser a principal fonte de $\mathrm{CO}_{2}$ dos fluidos de Montes Áureos. Outra fonte poderia ser o tonalito Itamoari, sintectônico, se o estudo de suas características petrológicas viesse a indicar derivação de um magma capaz de produzir fluidos ricos em $\mathrm{CO}_{2}$ durante o processo de cristalização. Um possível registro de fluidos de derivação magmática poderia advir das IF aquo-carbônicas saturadas, embora esses fluidos também possam resultar de aprisionamento de fluidos heterogêneos (Bowers \& Helgeson 1983, Crawford \& Hollister 1986).

As reações metamórficas podem gerar fluidos aquo-carbônicos de baixa salinidade a partir de $460-500^{\circ} \mathrm{C}$, envolvendo minerais máficos (Powell et al. 1991) e, segundo Kerrich (1990), fluidos metamórficos aquo-carbônicos são liberados durante o metamorfismo de rochas máficas hidratadas de fácies xisto verde e transição xisto verde a anfibolito $\left(450-500^{\circ} \mathrm{C}\right)$. Aceitando-se que a salinidade obtida para os fluidos aquo-carbônicos de Montes Áureos não seja superestimada, é possível que os valores mais altos e menos comuns (equiv. a $>8 \%$ em peso de $\mathrm{NaCl}$ ) reflitam a contribuição de fluidos aquosos magmáticos derivados da cristalização de corpos granitóides que ocorrem nas circunvizinhanças de Montes Áureos. Sob pressão de 2 kbar, magmas graníticos podem exsolver fluidos aquosos com salinidades superiores a $10 \%$ em peso de $\mathrm{NaCl}$ antes que $75 \%$ de sua história de cristaliza- ção tenha sido completada (Bodnar 1992).

$\mathrm{Na}$ verdade, as ferramentas metodológicas hoje empregadas produzem dados ainda insuficientes para definir, com maior clareza, a fonte dos fluidos que percolam zonas de cisalhamento. As evidências são ambiguas e satisfazem os atuais modelos de devolatilização tanto de rochas metamórficas como de magmas félsicos, particularmente aqueles que originam a suíte trondhjemitotonalito-granodiorito (Ridley \& Diamond 2000).

CONSIDERAÇÕES METALOGENÉTICAS Os dados texturais e de alteração hidrotermal permitem afirmar que as rochas hospedeiras do depósito de Montes Áureos foram submetidas a mais de um pulso hidrotermal durante as fases deformacionais sin e tarditectônicas. Os veios mineralizados são interpretados como tarditectônicos, nos quais o ouro foi depositado em pelo menos dois estágios após o pico do metamorfismo, levando à formação de pequenos corpos lenticulares e tabulares paralelos a subparalelos à foliação milonítica. $\mathrm{O}$ exato momento da precipitação do ouro é difícil de precisar, mas a ausência de deformação dúctil nos veios mineralizados sinaliza para um estágio de atenuação tectônica, tal como descrito em várias partes do mundo (Powell et al. 1991).

Os dados de IF em Montes Áureos dão pouco suporte à presença de complexos de cloreto como agentes transportadores do ouro, porquanto sua estabilidade é favorecida em fluidos oxidados $\left(\mathrm{SO}_{2} / \mathrm{H}_{2} \mathrm{~S}>1\right)$, ácidos, supersalinos e a temperaturas $>450^{\circ} \mathrm{C}$ (Gammons \& Williams-Jones 1997). A íntima associação do ouro com sulfetos permite inferir, por outro lado, que o transporte em Montes Áureos foi feito principalmente por complexos de enxofre, a exemplo de $\mathrm{Au}(\mathrm{HS})_{2}{ }_{2}^{-}$, o qual é dominante em fluidos pouco salinos a $\mathrm{T}<400^{\circ} \mathrm{C}$ (Gammons \& Williams-Jones 1997). A deposição poderia ter ocorrido de acordo com a reação $\mathrm{Au}(\mathrm{HS})_{2}{ }^{-}+\mathrm{FeO}=$ $\mathrm{Au}+\mathrm{FeS}_{2}+\mathrm{H}_{2} \mathrm{O}$, na qual o componente $\mathrm{FeO}$ provém da desestabilização de minerais máficos da rocha hospedeira pelos 

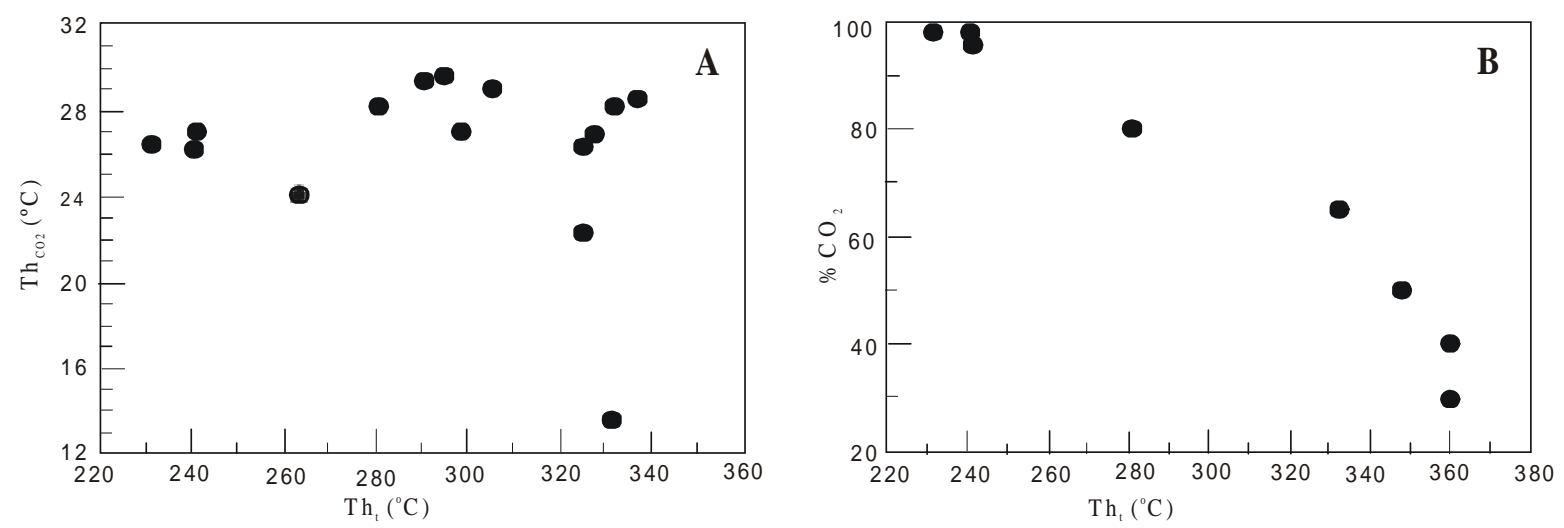

Figura $7-A)$ - Diagrama Tht x Th ${ }_{\mathrm{CO} 2}$ mostrando, salvo poucas exceções, o discreto aumento da temperatura de homogeneização da fase carbônica com o aumento da temperatura de homogeneização total das IF. B) - Diagrama $\mathrm{Th}_{t} \mathrm{x} \% \mathrm{CO} \mathrm{O}_{2}$ mostrando que as IF com maiores proporções de $\mathrm{CO}_{2}$ apresentam a temperatura de homogeneização total mais baixa.

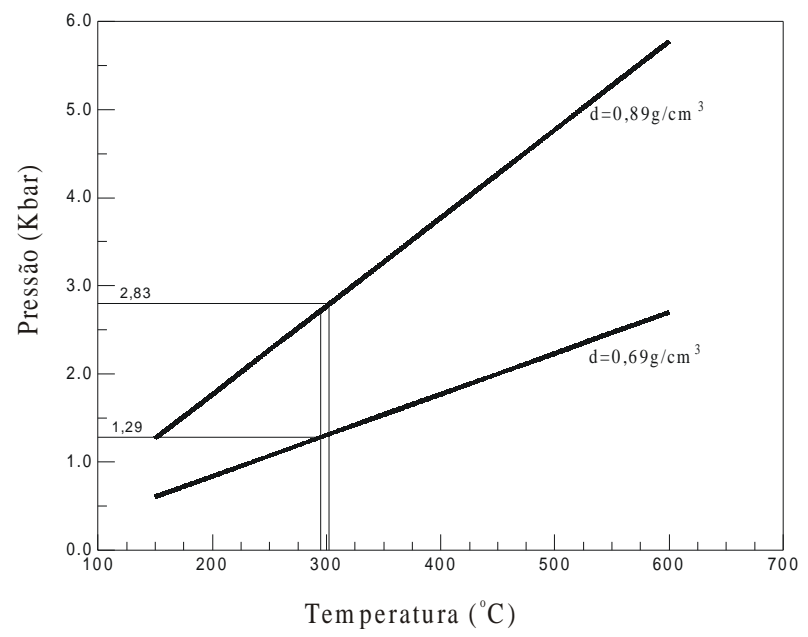

Figura 8 - Diagrama isocórico que permite estimar o intervalo de pressão (1,29 a 2,83 kbar) de aprisionamento dos fluidos aquo-carbônicos, com base no intervalo de temperatura fornecido pelo geotermômetro da clorita $\left(296\right.$ a $\left.302^{\circ} \mathrm{C}\right)$.

fluidos hidrotermais. A pouca abundância de sulfetos deve estar ligada à pouca abundância de minerais de ferro nas rochas metassedimentares ou a fluidos com baixo teor de espécies de enxofre e, portanto, com baixa capacidade de solubilizar o ouro, o que se reflete no caráter subeconômico do depósito de Montes Aureos. Localmente, porém, gradientes maiores da pressão dos fluidos, causados por processos rúpteis, poderiam ter sido suficientes para separar fases e ocasionar a precipitação de ouro livre em veios de quartzo (Mikucki 1998).

As feições texturais do minério e dos veios mineralizados, os padrões da deformação das rochas encaixantes e a transição fácies xisto verde e anfibolito, além das pressões de aprisionamento dos fluidos mineralizadores, indicam que a deposição do ouro deve ter ocorrido a profundidades de 5-10 km (Fig. 9). Segundo o modelo crustal contínuo proposto por Colvine et al. (1988), Groves (1993) e Groves et al. (1998), os depósitos auríferos em zonas de cisalhamento são formados em diferentes regimes e se distribuem ao longo de um perfil de aproximadamente $15-20 \mathrm{~km}$ sob tempera- turas de 180 a $700^{\circ} \mathrm{C}$ e pressões de < 1 até 5 kbar (Fig.9).

Embora na ausência de um sistema de veios de quartzo, que é uma das feições mais comuns dos depósitos de ouro arqueanos e proterozóicos hospedados em zonas de cisalhamento, (i) o ambiente tectônico, (ii) o controle estrutural, (iii) as associações mineralógicas, (iv) o tipo de alteração hidrotermal, (v) a relação temporal entre o evento hidrotermal e o pico do metamorfismo, (vi) o modo de ocorrência do ouro e sua relação com as rochas hospedeiras, assim como os dados físico-químicos dos fluidos mineralizadores, permitem classificar Montes Áureos como um depósito orogênico de ouro, semelhante aos que ocorrem em terrenos granito-greenstone de várias partes do mundo (Robert et al. 1997). A oeste do continente africano, em particular, os sistemas hidrotermais relacionados com a formação de vários depósitos de ouro hospedados em zonas de cisalhamento em terrenos précambrianos guardam muitas semelhanças com o depósito de Montes Áureos (Hammond \& Shimazaki 1994, Mumn Schmidt et al. 1997). No caso de o cráton São Luis vir a ser confirmado como fragmento do cráton Oeste Africano, essas características comuns podem apontar para processos semelhantes na formação da crosta continental dessas regiões cratônicas e altamente favoráveis a esse estilo de mineralização aurífera.

CONCLUSÕES A mineralização em Montes Áureos ocorreu tardi-tectonicamente, junto com a formação de um sistema de veios e vênulas compostos de quartzo, carbonato, arsenopirita, pirita e, subordinadamente, calcopirita. Os sítios mineralizados constituem corpos lenticulares e tabulares paralelos a subparalelos à foliação milonítica, com teores que não ultrapassam, em média, 2 ppm, tendo a mineralização ocorrido em duas etapas, uma envolvendo a precipitação de ouro granular em contato com os sulfetos, quartzo e carbonato, e a outra em microfraturas da arsenopirita e pirita.

Os fluidos mineralizadores aquo-carbônicos $\left(\mathrm{H}_{2} \mathrm{O}-\mathrm{CO}_{2} \pm \mathrm{CH}_{4}-\mathrm{NaCl}\right.$ $\pm \mathrm{MgCl}_{2} \mathrm{e} / \mathrm{ou} \mathrm{FeCl}_{2}$ ) foram provavelmente produzidos por reações de devolatização metamórfica em rochas metavulcanossedimentares contendo material carbonoso a temperaturas superiores a $450^{\circ} \mathrm{C}$, compatíveis com a transição da fácies xisto verde para anfibolito. Esses fluidos, ricos em $\mathrm{CO}_{2}$, apresentam baixa salinidade (eqüivalente a $2-8 \%$ em peso de $\mathrm{NaCl}$ ) e densidades de 0,6 a $0,89 \mathrm{~g} / \mathrm{cm}^{3}$, e foram aprisionados abaixo da temperatura do solvus, resultando em IF com diferentes razões $\mathrm{H}_{2} \mathrm{O} / \mathrm{CO}_{2}$. 
Salinidades mais altas (até eqüivalente a $15 \%$ em peso de $\mathrm{NaCl}$ ) são atribuídas principalmente à mistura com soluções magmáticas derivadas da cristalização de granitóides sintectônicos que afloram nas vizinhanças de Montes Áureos.

O ouro foi possivelmente transportado na forma de $\mathrm{Au}(\mathrm{HS})_{2}{ }^{-} \mathrm{e}$ depositado entre 260 e $350^{\circ} \mathrm{C}$, quando da desestabilização desse complexo e da interação entre os fluidos mineralizadores e as rochas encaixantes. Para temperatura em torno de $300^{\circ} \mathrm{C}$, estima-se que a mineralização ocorreu a pressões entre 1,3 e 2,8 kbar, correspondendo a profundidades de $4-8,5 \mathrm{~km}$.

Com a redução do fluxo termal do metamorfismo, as reações de descarbonização passaram a produzir menos $\mathrm{CO}_{2}$. Ademais, à medida que ocorria a precipitação de carbonato, os fluidos foram se empobrecendo em $\mathrm{CO}_{2}$, tornando-se progressivamente mais aquosos, o que deve ter ocorrido em torno de $200^{\circ} \mathrm{C}$. A esta temperatura, além do empobrecimento em $\mathrm{CO}_{2}$, pode ter também ocorrido mistura de fluidos aquo-carbônicos com fluidos aquosos independentes, mais superficiais, e de mais baixa temperatura e salinidade, e mais pobres em $\mathrm{Mg}$ e/ou Fe. Temperatura em torno de $85^{\circ} \mathrm{C}$ para os fluidos aquosos é admitida como a que marcou os estágios finais do sistema hidrotermal de Montes Aureos.

A composição química do ouro de Montes Áureos sugere uma deposição a temperatura inferior a $400^{\circ} \mathrm{C}$, compatível tanto com a temperatura mínima de aprisionamento dos fluidos mineralizadores, como a registrada pelo geotermômetro da clorita hidrotermal.

A escassez de sulfetos nas rochas encaixantes hidrotermalizadas pode ser atribuída ao fato de os minerais ricos em ferro serem pouco abundantes ou aos fluidos terem sido pobres em espécies de enxofre e que, mesmo favorecido pelas condições térmicas $\left(£ 450^{\circ} \mathrm{C}\right)$, o complexo $\mathrm{Au}(\mathrm{HS})_{2}{ }^{-}$,ou similar, não foi formado em quantidades suficientes para solubilizar grande quantidade de $\mathrm{Au}$. Isso deve ter contribuído, de certa forma, para a pouca eficácia dos fluidos em transportar ouro, o que se reflete nos baixos teores do depósito de Montes Áureos.

Embora de pequeno porte e sem apresentar grande complexidade litológica, o contexto geotectônico, os controles da mineralização, o tipo de alteração hidrotermal, a relação temporal entre o pico do metamorfismo e o evento hidrotermal, além das características físico-químicas dos fluidos mineralizantes, são da-

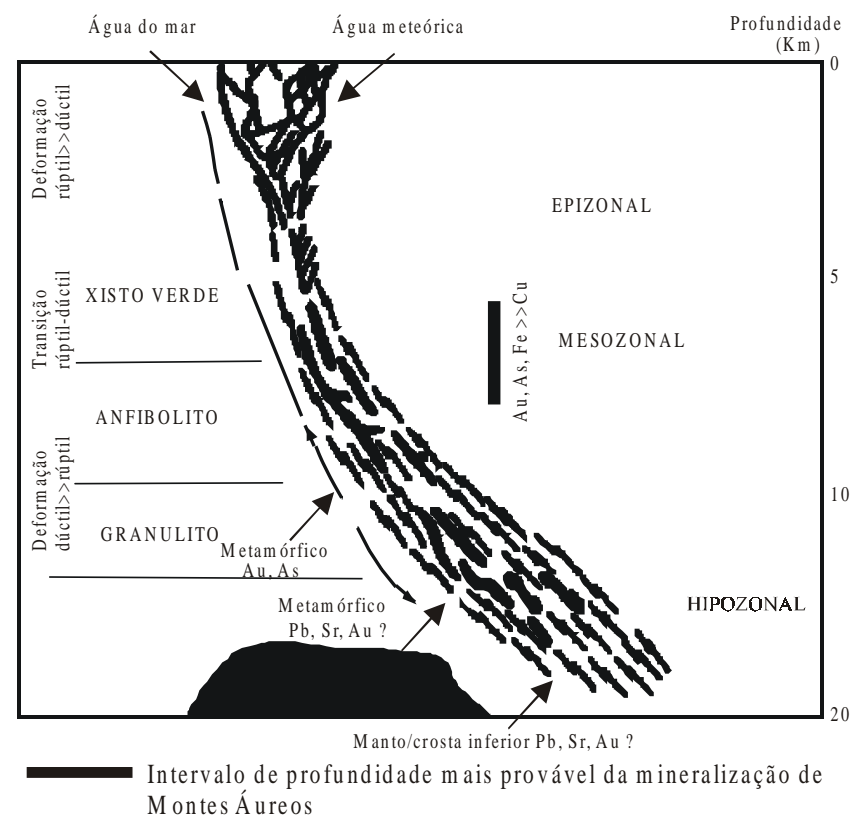

Figura 9 - Modelo crustal contínuo de formação dos depósitos de ouro em zonas de cisalhamento (Groves 1993, Groves et al. 1998), assinalando o intervalo de profundidade mais provável onde ocorreu a mineralização aurífera de Montes Áureos.

dos que permitem, no entanto, definir Montes Áureos como um depósito de ouro orogênico, similar aos que ocorrem em terrenos granito-greenstones arqueanos e proterozóicos evoluídos em ambientes colisionais.

Agradecimentos À Companhia de Mineração Chega Tudo pela cessão dos testemunhos de sondagem para realização deste estudo e ao professor Francisco de Assis Matos de Abreu que intermediou os contatos com essa empresa. Ao CNPq, o reconhecimento vem da concessão da bolsa de estudos ao primeiro autor. Aos revisores da RBG pelas sugestões ao manuscrito.

\section{Referências}

Abreu F.A.M de \& Lesquer A. 1985. Considerações sobre o Pré-cambriano da região sul-sudeste do Cráton São Luís. In: SBG, Simp. Geol. Amaz., 2, Belém, Anais, 1:7-21

Bodnar R. J. 1992. Can we recognize magmatic fluid inclusions in fossil systems based on room-temperature phase relations and microthermometric behavior? In: Hedenquist J. W. (ed.) Magmatic contributions to hydrothermal systems. Geol. Survey of Japan, Report \# 279, p. 26-30

Borges M.S., Costa J.B.S., Bermeguy R.L., Costa J.L., Maia R.G.N., Araújo O.J.B. 1994b. O quadro litoestrutural da Folha AS.23-V-C (Castanhal). In: SBG, Cong. Bras. Geol. 38, Camboriu, Anais, 2:113114

Borges M.S., Reis F.N., Costa J.B.S., Bermeguy R.L., Hasui Y. 1994a. Contribuição ao quadro geológico do município de Bragança, NE do estado do Pará. In: SBG, Simp. Geol. Amaz., 4, Belém, Boletim de Resumos Expandidos, p. 5-6
Bowers T.E. \& Helgeson H.C. 1983. Calculation of the thermodynamic and geochemical consequences of nonideal mixing in the system $\mathrm{H}_{2} \mathrm{O}$ $\mathrm{CO}_{2}-\mathrm{NaCl}$ on phase relations in geological systems: equation of state for $\mathrm{H}_{2} \mathrm{O}-\mathrm{CO}_{2}-\mathrm{NaCl}$ fluids at high pressures and temperatures. Geoch. Cosmoch. Acta, 47:1247-1275.

Cathelineau M. 1988. Cation site occupancy in chlorites and illites as a function of temperature. Clay Minerals 23:471-485

Cathelineau M \& Nieva D. 1985. A chlorite solid solution geothermometer. The Los Azufres (Mexico) geothermal system. Cont. Mineral. Petrol. 91:235-244

Chang Y.A., Goldberg D., Numamm J.P. 1977. Phase diagrams and thermodynamic properties of ternary copper-silver-gold. J. Phys. Chem., 6:621-674

Colvine A.C., Fyon A.J., Heather K.B., Marmont S., Smith P.M., Troop D.G. 1988. Archean lode gold deposit in Ontario. Ontario Geological Survey. 136p (Miscellaneous Paper 139). 
Condie E. K.C. 1981. Archean greenstone belts. Amsterdam, Elsevier. $434 \mathrm{p}$.

Costa J.B.S., Pastana J.M.N., Costa E.J.S., João X.S.J. 1988. Faixa de Cisalhamento Tentugal na folha SA.23-Y-B. In: SBG, Congr. Bras. Geol., 35., Belém, Anais, 5:2257-2268.

Crawford M.L. \& Hollister L.S. 1986. Metamorphic fluids: the evidence from fluid inclusions. In: V. Walther \& B.J. Wood (eds.). Fluid-rock interactions during metamophism. (Advances in Physical Geochemistry, 5), New York, Springer, 1-35.

Davis D.W., Lowenstein T.K., Spencer R.J. 1990. Melting behavior of fluid inclusions in laboratory-grown halite crystals in the systems $\mathrm{NaCl}-\mathrm{H}_{2} \mathrm{O}, \mathrm{NaCl}-\mathrm{KCl}-\mathrm{H}_{2} \mathrm{O}, \mathrm{NaCl}-\mathrm{MgCl}_{2}-\mathrm{H}_{2} \mathrm{O}$, and $\mathrm{NaCl}-\mathrm{CaCl}_{2}-$ $\mathrm{H}_{2} \mathrm{O}$. Geoch. Cosmoch. Acta, 54:591-601

Diamond L.W. 2001. Review of the systematics of $\mathrm{CO}_{2}-\mathrm{H}_{2} \mathrm{O}$ fluid inclsuions. Lithos, 55:69-99

Gammons C.H. \& Williams-Jones A.E. 1997. Chemical mobility of gold in the porphyry-epithermal environment. Econ. Geol., 92:45-59.

Goldstein R.H. \& Reynolds T.J. 1994. Systematics of fluid inclusions in diagenetic minerals. Tulsa, Society for Sedimentary Geology, 198p. (SEMP Short Course 31)

Groves D.I. 1993. The crustal continuum model for late-Archean lodegold deposits of the Yilgarn Block, Western Australia. Mineral. Depos., 28:366-374.

Groves D.I., Goldfarb R.J., Gebre-Mariam M., Hagemann S.G., Robert F. 1988. Orogenic gold deposit: a proposed classification in the context of their crustal distribution and relationship to other gold deposit types. Ore Geol. Rev., 13:7-27.

Hammond N.Q. \& Shimazaki H. 1994. Geology and geochemical aspects of ore formation at the Pretea mesothermal vein gold deposit in the Biriminian System of Ghana. Intern. Geol. Rev., 36:715-731.

Hasui Y., Abreu F.A.M. de, Villas R.N. 1984. Província Parnaíba. In: F.F.M. de Almeida \& Y. Hasui (coord.),O Pré-Cambriano do Brasil, São Paulo, Edgar Blücher, 36-44.

Hasui Y., Haralyi N.L.E., Costa J.B.S. 1993. Megaestruturação précambriana do território brasileiro baseada em dados geofísicos e geológicos. Geociências, 12:7-31.

Hollister L.S. 1990. Enrichment of $\mathrm{CO}_{2}$ in fluid inclusions in quartz by removal or $\mathrm{H}_{2} \mathrm{O}$ during crystal-plastic deformation. J. Struct. Geol., 12:895-901.

Hurley P.M., Almeida F.F.M., Melcher C.G., Cordani U.G., Rand J.R., Kawashita K., Vandoros P., Pinson W.H., Fairbairn H.W. 1967. Test of continental drift by comparison of radiometric ages. Science, 157:495-500

Kerrich R. 1990. Mesothermal gold deposits: a critique of genetic hypotheses. In: Robert F., Sheahan, P.A., Green, S.B. (eds). Greenstone gold and crustal evolution. Val d'Or, Geol. Assoc. Canada (NUNA Conference), 13-21.

Klein E. L. \& Moura C. A. V. 2001. Age constraints on granitoids and metavolcanic rocks of the São Luis craton and Gurupi belt, Northern Brazil: implications for lithostratigraphy and geological evolution. Intern. Geol. Rev., 43:237-253

Lowell G. \& Villas R.N.N. 1983. Petrology of nepheline syenite gneiss from Amazonian Brazil. Geol. Jour., 18:53-75

Mikucki E.J. 1998. Hydrothermal transport and depositional processes in Archean lode-gold systems: a review. Ore Geol. Rev., 13:307-321

Mineração Chega Tudo Ltda. 1997. Relatório de pesquisa para ouro realizado na região de Montes Áureos, estado do Maranhão. 7p. (inédito)
Mumn Schmidt A., Oberthür T., Vetter U., Blenkinsop T. G. 1997. High $\mathrm{CO}_{2}$ content of fluid inclusions in gold mineralizations in the Ashanti belt, Ghana: a new category of ore forming fluids? Mineral. Depos., 32:107-118

Palheta E. S. M. 2001. Evolução geológica da região nordeste do estado do Pará com base em estudos estruturais e isotópicos de granitóides. Centro de Geociências, Universidade Federal do Pará, Belém, Tese de Mestrado, $126 \mathrm{p}$.

Pastana J.M. do N. (org.). 1995. Turiaçu, folha SA.23-V-D, e Pinheiro, folha SA.23-Y-B: estado do Pará e Maranhão. Brasília, CPRM 205 p (Programa Levantamentos Geológicos Básicos do Brasil).

Parry W.T.1986. Estimation of $\mathrm{X}_{\mathrm{CO} 2}, \mathrm{P}$, and fluid inclusion volume from fluid inclusion temperature measurements in the system $\mathrm{NaCl}-\mathrm{CO}_{2}-$ $\mathrm{H}_{2} \mathrm{O}$. Econ. Geol., 81:1009-1013.

Powell R., Will T.M., Phillips G.N. 1991. Metamorphism in Archean greenstone belts: calculated fluid compositions and implications for gold mineralization. J. Metam. Geol., 9:141-150.

Ridley J. R. \& Diamond L.W. 2000. Fluid chemistry of orogenic lode gold deposits and implications for genetic models. In: S.G. Hagemann \& P.E. Brown (ed.) Gold in 2000, p.141-162 (Reviews in Economic Geology 13)

Robert F., Poulsen K.H., Dubé B. 1997. Gold deposits and their geological classification. In: Decennial International Conference on Mineral Exploration, 4. Proceedings of Exploration 97:209-220 (Exploration Geochemistry Paper, 29)

Roedder E. 1984. Fluid Inclusions. Mineral. Soc. Am., 644p, (Reviews in Mineralogy 12).

Seitz J. C. \& Pasteris J. D. 1990. Theoretical and practical aspects of differential partitioning of gases by clathrate hydrates in fluid inclusions. Geoch. Cosmoch. Acta 54:631-639

Shepherd, T.J., Rankin, A.H., Alderton, D.H.M. 1985. A practical guide to fluid inclusion studies. Glasgow, Blackie \& Son Ltd., 293p.

Sibson R.H., Robert, F., Pousen K.H. 1988. High-angle reverse faults, fluid-pressure cycling, and mesothermal gold-quartz deposits. Geology, 16:551-555

Swanenberg H.E.C. 1979. Phase equilibria in carbonic systems, and their application to freezing studies of fluid inclusions. Contr. Mineral. Petrol., 68:303-306

Takenouchi, S. \& Kennedy, G.C. 1965. The solubility of carbon dioxide in $\mathrm{NaCl}$ solutions at high temperatures and pressures. Amer. J. Sci., 263:445-454.

Villas R. N. 1982. Geocronologia de intrusões ígneas na bacia do rio Guamá. In: SBG, Simp. Geol. Amaz. 1, Belém, Anais, 1:233-247

Villas R. N. 2001. O granito de duas micas Ney Peixoto, nordeste do estado do Pará: caracterização petrográfico-petroquímica e contexto tectônico. In: SBG, Simp. Geol. Amaz. 7, Sessão Temática 10, Belém

Yamaguti H.S. 2000. Mineralização aurífera de Montes Áureos (Maranhão): rochas hospedeiras, controles deposicionais e fluidos mineralizantes. Centro de Geociências, Universidade Federal do Pará, Belém, Tese de Mestrado, 79 p.

Zang W. \& Fyfe W.S. 1995. Chloritization of the hydrothermally altered bedrock at the Bahia gold deposit, Carajás, Brazil. Mineral. Depos., 30:30-38

Manuscrito A-1277

Recebido em 16 de novembro de 2001

Revisão dos autores em 02 de fevereiro de 2003 Revisão aceita em 10 de fevereiro de 2003 